\title{
WestVirginiaUniversity
}

THE RESEARCH REPOSITORY @ WVU

Graduate Theses, Dissertations, and Problem Reports

2008

\section{Effects of rate of feedback and reinforcement on novel responding}

Vennessa L. Walker

West Virginia University

Follow this and additional works at: https://researchrepository.wvu.edu/etd

\section{Recommended Citation}

Walker, Vennessa L., "Effects of rate of feedback and reinforcement on novel responding" (2008).

Graduate Theses, Dissertations, and Problem Reports. 2727.

https://researchrepository.wvu.edu/etd/2727

This Dissertation is protected by copyright and/or related rights. It has been brought to you by the The Research Repository @ WVU with permission from the rights-holder(s). You are free to use this Dissertation in any way that is permitted by the copyright and related rights legislation that applies to your use. For other uses you must obtain permission from the rights-holder(s) directly, unless additional rights are indicated by a Creative Commons license in the record and/ or on the work itself. This Dissertation has been accepted for inclusion in WVU Graduate Theses, Dissertations, and Problem Reports collection by an authorized administrator of The Research Repository @ WVU.

For more information, please contact researchrepository@mail.wvu.edu. 
Effects of rate of feedback and reinforcement on novel responding Vennessa L. Walker

Dissertation submitted to the Eberly College of Arts and Sciences at West Virginia University in partial fulfillment of the requirements

for the degree of

Doctor of Philosophy

in

Psychology

Philip N. Chase, Ph. D., Chair

Michael Perone, Ph. D.

K. Andy Lattal, Ph. D.

Steven Branstetter, Ph. D.

Laura Pyzdrowski, Ed. D.

Department of Psychology

Morgantown, West Virginia

2008 


\begin{abstract}
Effects of rate of feedback and reinforcement on novel responding
\end{abstract}

Vennessa L. Walker

Ten middle-school students were assigned to receive feedback and token reinforcement either every $1 \mathrm{~min}(\mathrm{HR})$ or every $15 \mathrm{~min}(\mathrm{LR})$. Subjects used a computer program to learn to perform 5 basic algebra skills at high rates and high accuracy. Subjects were yoked with a partner for practice so that each member of the pair completed the same number of items per skill. Subjects were provided with cumulative review worksheets and then were tested for distraction, adduction, and retention. Results suggest that HR facilitates faster acquisition of skills as well as better performance on cumulative reviews, distraction, and retention tests. Subjects were generally unable to complete the adduction items, suggesting that the current procedures may be inadequate for producing generalization of skills. 


\section{Acknowledgments}

First, I would like to thank the members of my committee for their time and insight: Andy Lattal, Mike Perone, Steve Branstetter, Laura Pyzdrowski, and Phil Chase. I also would like to thank my research assistant, Lauren Cook, for her many hours of dedication to this project. Additionally, I would like to thank my current student assistant, Jennifer Schwartzbeck, for her help with the IOA task. I especially would like to recognize my chair, advisor, and mentor, Phil Chase, for whom I have the utmost respect and admiration. This dissertation is a product of, and a testament to, his steady guidance, patience, and insight. I also would like to thank my Verbal Behavior labmates for 6 wonderful years of intellectual, professional, and personal development and support. Special thanks also to Harold Lobo and Chris Rice, who were invaluable resources during the arduous programming process.

This dissertation would never have been accomplished without the unwavering support of my family - Dad, Mom, sisters and brothers, nieces and nephews - thank you for your sacrifices and for believing in me. I'm glad I can finally answer the question, “When are you done?” I also never would have made it through without my surrogate family - Misty, Christy, Libby, Harold, Dave - you carried me through some of my most difficult times and kept my faith strong. From the bottom of my heart, thank you.

Finally, I dedicate this dissertation to my son, Caleb, who has given my life joy and meaning beyond any I thought possible. I thought it would be a miracle to finish this dissertation, but the true miracle in my life came on December 14, 2007. I love you so much. 


\section{Table of Contents}

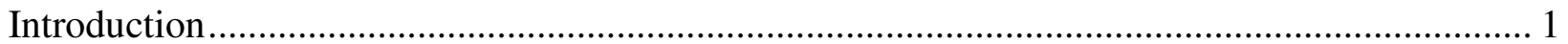

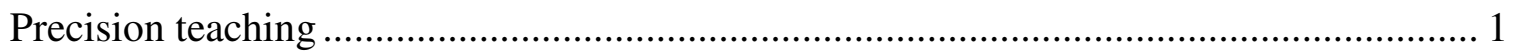

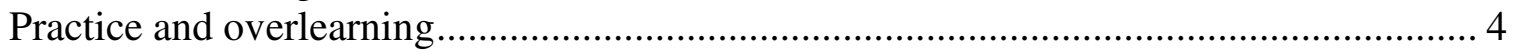

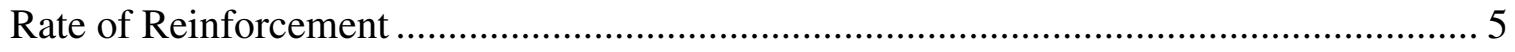

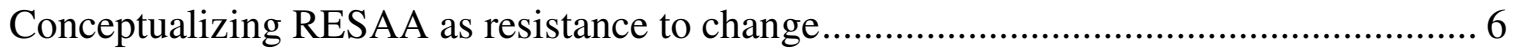

Previous research on rate of reinforcement in precision teaching .................................. 7

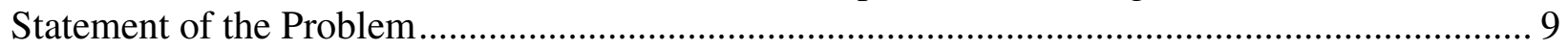

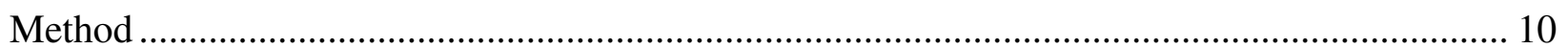

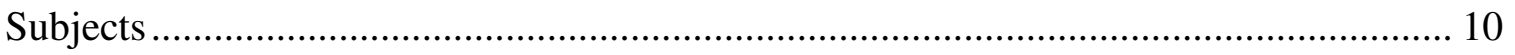

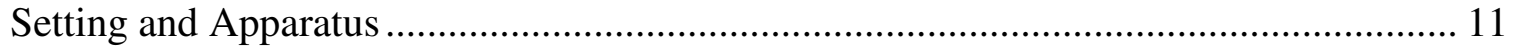

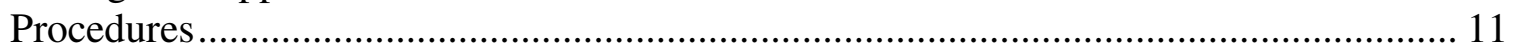

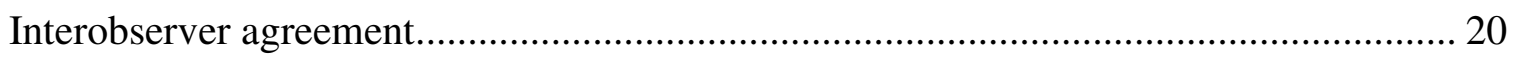

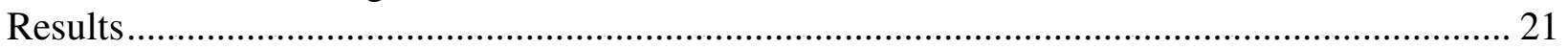

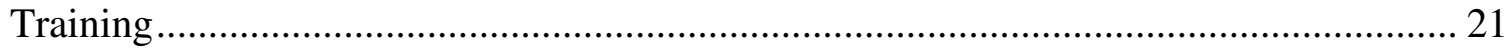

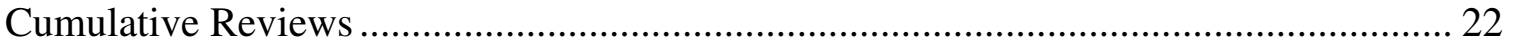

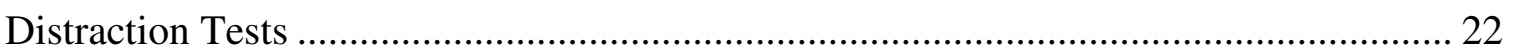

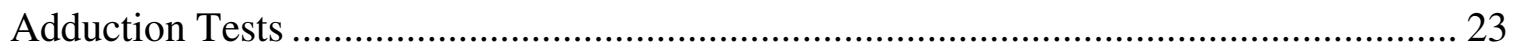

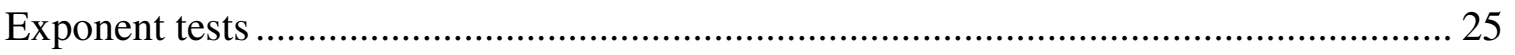

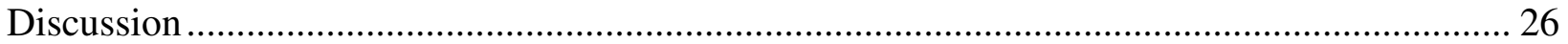

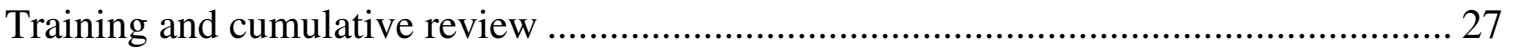

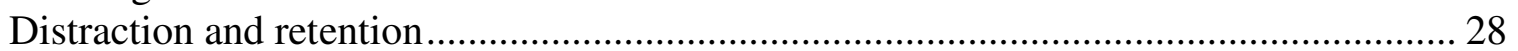

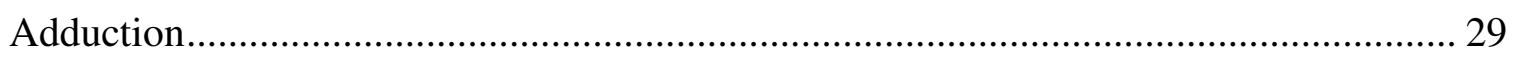

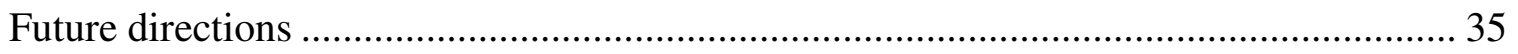

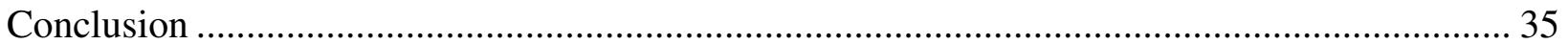

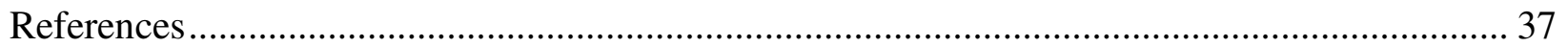

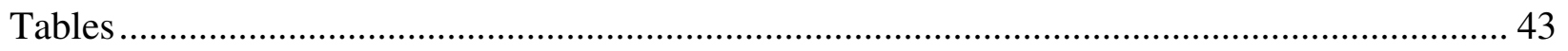

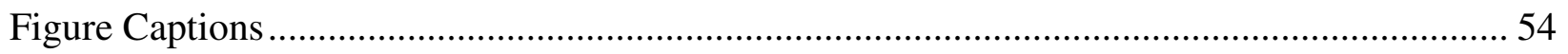

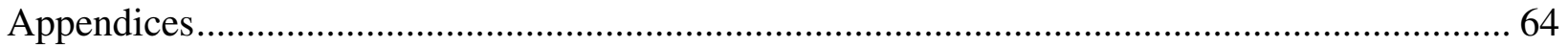


Effects of rate of feedback and reinforcement on novel responding

According to a report from the Trends in International Mathematics and Science Study (TIMSS), American elementary-aged children exceed many of their international counterparts in mathematics (Mullis, Martin, \& Foy, 2005). Starting with middle school, however, a significant discrepancy between American students' mathematical achievement and their international peers emerges that persists throughout secondary education. In these critical middle school years, students are introduced to mathematical content, such as Algebra and Geometry, which serve as the foundation for other areas such as advanced Algebra, Trigonometry, and Calculus. Clearly there is a breakdown in students' training beginning with these core areas, and improvements in training are needed to overcome these deficits. Recent research in behavioral education has examined various methods of training mathematical skills to find efficient and effective ways to deliver instruction (e.g., Chiesa \& Robertson, 2000; Kim, 2003; Mayfield \& Chase, 2002; Neef, Nelles, Iwata, \& Page, 2003). Identifying the critical components of these methods might help solve some of the problems encountered with middle school mathematics.

\section{Precision teaching}

One method of behavioral education is precision teaching (e.g., Chiesa \& Robertson, 2000; Hartnedy, Mozzoni, \& Fahoum, 2005; Singer-Dudek \& Greer, 2005). Precision teaching is an individualized method of instruction that focuses on measuring students' rate of responding over repeated sessions. Precision teachers start with a target, or composite task, and analyze its components to determine the necessary prerequisite skills. Training is conducted on component skills until students meet specified rate and accuracy criteria. For instance, a problem within a basic arithmetic curriculum might be $2+6-4=$ ?. This composite skill involves the component skills of number recognition, addition, and subtraction to solve the problem. Each of these 
component skills would be instructed and then students would be given timed assessments, typically in 1-min assessments or timings, to determine whether their responding was both accurate and fast (e.g., Miller, Hall, \& Heward, 1995). Typically, accuracy criteria of $90 \%$ or better and rate criteria that vary depending on the component skills are set as aims, and the student continues to practice the skills until the accuracy and rate aims are achieved.

The use of 1-min timings allows students to receive immediate feedback on their performance, and performance deficits can be identified and rectified. If students are not reaching their accuracy or rate aims, further component analyses may be required to correct the areas of deficient performance. In the previous example, if a student is not meeting the rate criterion for mastery, a precision teacher may provide number writing drills to increase the speed with which the student can write numerals. As number writing is a prerequisite skill for writing mathematical solutions, it may be necessary to address number writing as a separate component skill if the situation warrants.

Once the component skills are trained to targeted rates and accuracy, the precision teaching literature suggests that important behavioral outcomes will result (e.g., Lindsley, 1992). These outcomes have been referred to as: Retention, Endurance, Application, and Performance Standards (REAPS; Binder, Haughton, \& Van Eyk, 1990) and Retention, Endurance, Stability, Application, and Adduction, or RESAA (Johnson \& Layng, 1996). RESAA differed from REAPS because it separated Stability from Endurance and also separated Application and Adduction, or problem solving. Due to its specificity of outcomes, RESAA will be defined and used in this dissertation.

The first outcome of RESAA is Retention. Retention refers to engaging in a behavior after a period of time has elapsed between training and testing, with no practice occurring during 
the interim. For example, a student would be tested 2 weeks after completing training on a skill without having practiced that skill during those 2 weeks. The second outcome, endurance, involves persistence in the behavior for an extended period of time without breaks. For example, a skill may be practiced using 1-min timings, and to measure endurance, subjects would be given a 5-min timing. Stability refers to engaging in a behavior in the face of disruptors, like distracting noises and movements present in the test environment. Retention, endurance, and stability tests all use items similar to the ones the students answered during training. The fourth outcome, application, refers to the response occurring in new contexts. The discriminative stimulus for the response is embedded among other stimuli that are not discriminative for the behavior. Application is often referred to as providing a "real-world" context for mathematical principles. For instance, one might learn to calculate the area of a rectangle, and an application question for that skill might ask the student to determine how many square feet of carpet would be necessary to cover the floor in a particular room. In this case, the only relevant stimuli for answering the question are related to identifying the room as a rectangle and applying the area formula. The final RESAA outcome is adduction. Adduction requires a novel recombination of skills in the presence of novel stimuli, a situation often described as a problem, such as in problem solving. If one learned how to add and subtract, but the combination of the two skills had never been reinforced, then $2+6-4=$ ? constitutes a problem, and recombination of those two repertoires to arrive at the solution would constitute adduction.

One problem with precision teaching research is that it generally has failed to assess a range of fluency outcomes (Doughty, Chase, \& O’Shields, 2004). Most studies of precision teaching are demonstrations of the effectiveness of precision teaching in acquiring certain skills (e.g., Brunner, McLaughlin, \& Sweeney, 1993; Van Houten \& Thompson, 1976). Moreover, the 
few studies that have experimentally assessed fluency outcomes have focused mainly on retention (e.g., Bullara, Kimball, \& Cooper, 1993; Shirley \& Pennypacker, 1994; Young, West, $\&$ Crawford, 1985). A second problem with precision teaching is its emphasis on rate-building, requiring students to achieve a targeted rate standard on component skills before being allowed to progress in a curriculum. Even when precision teaching has been demonstrated to positively affect a fluency outcome, the studies are limited by lack of experimental control. Variables such as practice, overlearning, and reinforcement rate, which have been shown in other research to improve student performance (Doughty, Chase, \& O'Shields, 2004), may be responsible for changes in student performance. Thus, an analysis of these variables as they pertain to precision teaching practices may reveal the critical procedures that contribute to fluency outcomes.

\section{Practice and overlearning}

Practice refers to repeatedly engaging in a particular response, particularly in the course of acquisition or maintenance of the response. Subjects in precision teaching studies are often compared to their peers in a normal classroom setting (e.g., Chiesa \& Robertson, 2000). By virtue of the methods used in precision teaching, such as practice worksheets and timed probes, students exposed to precision teaching methods typically receive more practice with the skills trained. This additional practice, in turn, may be responsible for the positive effects of precision teaching methods (Rohrer, Taylor, Pashler, Wixted, \& Cepeda, 2005).

The additional practice provided in precision teaching may also result in another training procedure known as overlearning, which may lead to increased performance with the worksheets and timed probes used in precision teaching. Overlearning refers to additional practice provided on a skill after a mastery criterion is met (Driskell, Willis, \& Copper, 1992; Gilbert, 1957). It is typical in precision teaching for the students to meet a mastery criterion of $90 \%$ correct and then 
receive timed probes beyond this mastery level in order to reach a rate of at least 60 responses per minute. These extra probes provide overlearning on the skill.

\section{Rate of Reinforcement}

Although practice and overlearning have been shown to be effective procedures for producing outcomes such as retention (e.g., Driskell, Willis, \& Copper, 1992; Gilbert, 1957; Rohrer, Taylor, Pashler, Wixted, \& Cepeda, 2005), reinforcement rate is another factor that has not been sufficiently addressed in the precision teaching research. Basic research in behavior analysis has identified reinforcement rate as a critical variable affecting behavioral persistence, or resistance to change. Resistance to change has been described in the basic behavior analytic literature as behavioral momentum, which is based on an analogy to momentum used in physics (Nevin, Mandell, \& Atak, 1983). According to physics, momentum is a function of an object's velocity and mass. The more momentum an object has, the less likely it is to be hampered by an outside force. Likewise, the model for behavioral momentum postulates that responses with higher momentum are less likely to be disrupted by external forces.

Nevin and his colleagues liken velocity to response rate and mass to external or independent variables like rate of reinforcement. Disruptors have typically included procedures such as extinction and response-independent reinforcement, although research with humans has also included reversals of trained discriminations, and audio and visual distractions. Research has

shown that a critical factor influencing behavioral momentum is reinforcement rate (e.g., Dube \& McIlvane, 2002; Lattal, 1989; Nevin, Mandell, \& Atak, 1983). Dube and McIlvane, for instance, trained developmentally delayed children to perform simple discriminations. Performance was reinforced on either a continuous reinforcement (CRF) or variable-ratio (VR) schedule. When the contingencies were reversed, the discriminations trained using a CRF schedule did not 
reverse as readily to align with the new contingencies as those trained using a VR schedule. That is, for the discriminations trained using a richer reinforcement schedule, subjects' behavior persisted more than those trained on the leaner schedule.

\section{Conceptualizing RESAA as resistance to change}

As a set of behaviors, the outcomes of RESAA can be conceptualized in terms of resistance to change or behavioral persistence. Retention, for instance, requires the maintenance of a skill over a prolonged period of non-practice. The behavior must persist when the discriminative stimuli are presented after a long delay. Endurance involves persistence in the behavior over a longer time period than that used during training. Thus, both retention and endurance require behavioral persistence in the face of temporal disruptors. Stability and application involve persistence in the presence of irrelevant or extraneous stimuli. In each of these outcomes, stimuli other than those critical to the task may disrupt behavior, but for the behavior to be reinforced, it must persist despite the disruption. Stability requires that the behavior persist under external distraction conditions, such as audio or visual stimuli. In an application task, discriminative stimuli are embedded in a novel context. The novel context involves stimuli that might interfere with control by the discriminative stimuli.

Adduction is not usually conceptualized as resistance to change, but it does involve the persistence of one or two sets of responses. When a problem is presented in an adduction task, the stimuli do not occasion a behavior that has been previously reinforced, but rather the stimuli are discriminative for variations, patterns, or combinations of responding that lead to the solution (Skinner, 1969). In other words, the stimuli present in a problem situation are discriminative for variations in behavior. Thus, solutions may be derived from behavioral variation being resistant to change (Neuringer, 2003). This often has been referred to as trial and error and the persistence 
of trial and error responding may result in the solution to the problem. Often, however, the stimuli in an adduction task are discriminative for the particular responses that are varied. For example, the problem $2(6)+3=$ ? provides discriminative stimuli for multiplication and addition, but neither response by itself will solve the problem. Likewise, simply varying any behavior will not solve the problem. Instead if both multiplication and addition responses as well as varying the order in which they occur are resistant to change, then the particular pattern of multiplying before adding might occur to arrive at the solution.

Precision teaching might facilitate resistance to change because it provides students with ample opportunities for not only practice and overlearning, but it also provides a substantial amount of feedback and purported reinforcement. If RESAA outcomes are produced in accordance with resistance to change, then skills that are trained with higher rates of reinforcement should result in higher levels of RESAA performance than skills trained with lower reinforcement rates. If the consequences used in precision teaching function as reinforcement, then reinforcement rate may be a critical factor that elevates the performance of precision teaching students above that of their peers who are given a standard curriculum (e.g, Chiesa \& Robertson, 2000).

Previous research on rate of reinforcement in precision teaching

Previous research (Walker, 2005) has attempted to examine the impact of reinforcement rate on fluency outcomes, but the results were inconclusive. In that study, female college students were divided into two groups and trained to perform algebra skills at high rates and high accuracy. One group received corrective feedback on their performance every minute, and the other group received corrective feedback once every five minutes. Four problems have been identified with this study. First, although the ratios of reinforcement experimentally manipulated 
in that study (1:5) exceeded those used in basic animal studies of behavioral momentum (1:4), the ratios may be more comparable to each other than the differences found between typical and precision teaching classrooms. For example, if a teacher in a typical classroom gives in-class worksheets, the teacher might collect the worksheets, grade them all at once, and then return them the following day (e.g., Van Houten \& Thompson, 1976). The rate of consequences in this case will be once a day and less than the once a minute consequences provided with typical precision teaching procedures. Even if the teacher graded the worksheets immediately after collecting them, there would still be a lag between completion of the worksheet and delivery of feedback and/or reinforcement because the teacher would be grading all of the worksheets before returning them to the students. In contrast, the timings and practice worksheets used in a precision teaching classroom are graded immediately by a teacher, aide, or peer; thus, the delay to feedback is ostensibly much shorter than in a typical classroom situation. Providing differences in reinforcement rate that better approximate these differences in classrooms might be necessary to find differential effects in student responding.

Another potential problem in the previous study involved the subject population used (college students). These subjects likely had pre-experimental exposure to all of the skills being trained: 5 rules for manipulating exponents. Thus, it is highly likely that the curriculum strengthened previously learned behaviors rather than providing a means for acquisition of new responses. This may have made any changes in the performance measured in the experiment less sensitive to the manipulations of rate of reinforcement.

The motivational conditions may not have been sufficiently addressed in the previous study as well. Money was used as a reinforcer and it was possible that money did not function as a reinforcer for some participants' responding. As a generalized conditioned reinforcer, money 
may not be as effective as more specific consequences that can be provided. For example, Dube and McIlvane (2002) used a token reinforcement system. In a token system, subjects earn plastic chips, coupons, points or other symbols that can be exchanged for a back-up reinforcer of the students' choice. Typically an array of back-up reinforcers is provided, and each back-up reinforcer "costs" a certain number of tokens. Subjects earn tokens for their performance and periodically trade their tokens for a back-up reinforcer. In general, token systems have been effective for a wide range of behaviors (e.g., Boniecki \& Moore, 2003; Miller \& Schneider, 1970; Wolf, Giles, \& Hall, 1968). Token systems have been used effectively in educational settings to increase selection of math tasks over other activities, using stickers, yoyos, and other toys as the back-up reinforcers (McGinnis, Friman, \& Carlyon, 1999). Token systems have also been effective at increasing accuracy on math tasks, when free time, games, and other leisure activities are used as the back-up reinforcers (Swain \& McLaughlin, 1998). Thus, if a sufficient array of back-up reinforcers is provided from which the subjects can choose, tokens may be effective conditioned reinforcers that can mediate the time between the response and receipt of the back-up reinforcer.

Finally, practice and overlearning were not controlled in Walker (2005); thus, any possible effect of manipulating reinforcement rate may have been offset by variability from the pre-experimental history, practice, or overlearning effects. Continued investigations of the effects of reinforcement rate on fluency outcomes within precision teaching that minimize these difficulties and confounds are needed.

\section{Statement of the Problem}

Precision teaching suggests that training component skills to high accuracy and rate criteria will result in important behavioral outcomes known as RESAA. Although research in 
precision teaching has demonstrated its effectiveness in comparison to standard classroom instruction on outcomes such as retention, it is unclear whether precision teaching produces any of the other outcomes of RESAA. Even in those cases where precision teaching produces retention, it remains uncertain which components of precision teaching are critical to producing the outcome. The possibilities include a richer reinforcement rate, extensive practice, or overlearning. In particular, if RESAA can be conceptualized as involving behaviors that are resistant to change, then the behavioral momentum literature suggests that reinforcement rate might be the critical factor that produces this persistence. The current study examined effects of reinforcement rate on retention, stability, and adduction while controlling for practice. In addition, the present experiment used middle-school children and a token economy system and feedback as potential reinforcers. The token economy exchange system should better address the problems associated with motivational operations, as the subjects selected back-up reinforcers towards which to work. In addition, the middle school children were selected on the basis of having not yet acquired the skills taught during the experiment.

Method

Subjects

Ten middle school students (grades 5-7, ages 10-13) participated in this experiment. According to the West Virginia State Content Standards and Objectives, the skills that were taught in the experiment are typically learned in the $7^{\text {th }}$ grade. Therefore, most middle school students had not been exposed to the experimental skills, but should have acquired the basic skills (e.g., multiplication, subtraction) necessary to complete the tasks. To assure their skill level, subjects had to meet the criteria on the Basic Skills and Exponent Skills pretests as described below. Subjects who met the eligibility requirements were students who had the 
prerequisite arithmetic skills to learn to manipulate exponents but who did not yet manipulate exponents correctly. Subjects received the experimental training procedures in pairs. Each pair received the same amount of practice on the training items, but varied in terms of the rate of feedback and reinforcement received. Although members of the pairs were randomly assigned to a condition, the member who was older and in a higher grade was assigned to the Low Reinforcement group (described below) in all cases. Subjects and their parents received a cover letter and signed an informed consent form and assent form (Appendix A) prior to participation.

\section{Setting and Apparatus}

Sessions were conducted in a school computer laboratory or in a laboratory carrel measuring approximately $2 \mathrm{~m} \mathrm{x} 2 \mathrm{~m}$. The subjects were provided a desk, chair, computer, and headphones. A computer screen displayed the instructions, examples, worksheets, and feedback during the session. Scrap paper was provided for the subjects' use during the session. The computerized portion of the study was programmed using Microsoft Visual Basic 6.0. During the session, the experimenter remained at another desk so as not to disturb the subject, and only interacted with the subject as necessary and outlined below. Exercises were timed by the computer.

\section{Procedures}

The experiment involved 6 steps as outlined in Table 1 and are described below.

Reinforcement procedures. Subjects earned money toward gift certificates from a range of local stores such as Target, Old Navy, and Barnes \& Noble. Prior to the pretests, the token system was explained to the subjects. Subjects were told that they would be working for gift certificates to a store of their choosing. Prior to the first session, the subject indicated which store's gift certificate would serve as the back-up reinforcer. The subject's earnings accumulated 
for that store until at least $\$ 5.00$ had been earned. At the beginning of the following session, subjects again were asked to make a selection regarding which store to allocate their next $\$ 5.00$ in earnings. Subjects could continue to earn money towards the same store they selected previously or change stores. If subjects changed stores, they had to accumulate at least $\$ 5.00$ towards that store before they were given the option to change stores again. If the subjects chose to continue earning money towards the same store, the option to stay or switch was presented at the beginning of each session. Earnings were based on subjects' performances on the pretests, training worksheets, review worksheets, and tests. At the end of each day, subjects were told how much money they had earned for each store. Subjects were given their gift certificates at the conclusion of the study.

Pretesting. Subjects were given a series of pretests to determine whether they met the eligibility requirements for the study. The first pretest was a Basic Skills pretest (Appendix B). This pretest was comprised of 50 addition, subtraction, multiplication, division items, and also included variables. Items on the pretest did not require the participants to combine operations, however. There were 3 parallel versions of this pretest. Items on the Basic Skills pretest were presented on the computer, with 4 multiple-choice options per item. Subjects were required to score at least $90 \%$ on the Basic Skills pretest to continue in the study; otherwise, they were excused from the study. Subjects also were required to reach the $90 \%$ criterion within a certain time limit as determined by an expert group, described below. The time criterion was used to ensure that subjects were proficient with the basic skills, as this may have impacted their performance during the timings. If subjects reached the accuracy criterion, but not the rate criterion, they were given another version of the Basic Skills test to try to improve their rate. If 
subjects failed to reach both the accuracy and rate criteria within 3 administrations, they were dismissed from the study.

Subjects who passed the Basic Skills test were given an Exponent pretest (Appendix C) to ensure that they were not able to perform the 5 skills trained in the study: 1) multiplying exponents, 2) dividing exponents, 3) raising exponents to a power, 4) finding the roots of exponents, and 5) order of operations. The Exponent pretest consisted of 25 items, with 5 questions for each skill. This pretest was administered on paper because the test uses a constructed-response format similar to subsequent tests. Subjects were required to score $28 \%$ or less on the Exponent pretest to continue in the study; subjects who scored above this threshold were dismissed. If subjects failed to answer at least $28 \%$ of the questions correctly, they were told which items were answered incorrectly, although they were not given corrective feedback. Subjects who failed to meet the $28 \%$ accuracy criterion were given a series of 3 administrations of the Exponent pretest to ensure that they could not acquire the skills simply through knowledge of results. Subjects who scored $28 \%$ or less on each of the 3 administrations were allowed to continue in the study.

The third pretest was the Adduction pretest (Appendix D). The Adduction pretest consisted of 25 items that incorporated multiple operations and skills within each item. There were 8 items each combining 3 and 4 skills and 9 items combining all 5 skills. The Adduction test was a written test and required constructed responses. There were 7 parallel versions of the test for use during pretesting, adduction testing after each skill was trained, and retention testing; however, each test involved a unique set of constants, variables, and operations. The combinations of operations and skills required to answer these questions are purported to constitute novel responses for these subjects. For instance, an adduction item might be $\left(2 h^{2}\right.$. 
$\left.2 h^{5}\right)^{4}$, which involves combining 3 skills: order of operations, multiplying coefficients and variables with exponents, and raising variables and exponents to a power. Subjects who answered any of the adduction problems correctly on the pretest were dismissed. Those who did not answer any of these items correctly were selected to participate in the study.

Pretraining. To ensure that subjects had basic square and square root skills, they were provided with a worksheet teaching them the squares of all numbers between 1 and 12, as well as the square roots of all the squares of the numbers between 1 and 12. Subjects were required to complete 3 worksheets of 24 questions with $100 \%$ accuracy before continuing on to the training. Subjects earned $\$ 1.50$ for completing pretraining.

Training conditions. Individual sessions were conducted approximately 5 times per week and lasted approximately $2 \mathrm{hr}$ each. Subjects were assigned to either the High or Low Reinforcement group by randomly assigning the first subject in each pair, and the counterpart was automatically assigned to the alternative group. Both groups received training in blocks of 15 timings. The lone exception occurred on Rule 1 for Pair 1, who received training in blocks of 30 timings. Both subjects reported extreme fatigue with the 30-timing format, so the blocks were reduced to 15 timings for all subsequent rules and subjects. In the High Reinforcement (HR) group, subjects were given feedback on their performance after each timing. For the Low Reinforcement (LR) group, subjects were given feedback on their performance only for the last $\left(15^{\text {th }}\right)$ timing. At the end of the designated timing, a pop-up screen instructed the subject to review the feedback for that timing. Thus, the feedback ratio between the HR and LR groups maximized the difference between reinforcement rates within the time restrictions of the study. Earnings were accumulated for all of the timings and were reported to the subject at the end of the day. Prior to the first training session, the experimenter read the instructions to the subject to 
ensure that the subject understood the task and had no questions. The instructions on the screen for all skills read:

You will be learning some math skills. You'll be given instructions for each skill as well as examples showing how to use the skill. You will then be given some problems using that skill. Do as many problems as you can as quickly as possible, but be careful when you click your answers, because once you click an answer, you cannot change it. The more problems you get right and the fewer mistakes you make, the more money you will earn towards your gift certificate. If you answer fast enough with few mistakes, you will earn 5 cents. If you can use this skill correctly and fast enough in the first 15 minutes, you will earn a $\$ 1.00$ bonus.

If you do not learn to use the skill correctly and fast enough, you can still earn 2 cents each time you get faster, as long as you get the problems correct. There is scrap paper if you need it. When 1 minute is over, a new box will appear. Pay attention to what the box says and follow the instructions. If you don't have any questions, please put on the headphones and click the button below to continue.

Subjects in both conditions were required to achieve an accuracy rate of $90 \%$ to receive points. If subjects met the terminal rate with $90 \%$ accuracy, they earned 5 cents toward their store gift certificate. If subjects failed to reach the terminal rate, they could still earn 2 cents by improving on their best previous performance by $1.25 \mathrm{x}$ while still maintaining $90 \%$ accuracy. The criterion of $1.25 \mathrm{x}$ is based on a minimum acceleration criterion described by White and Haring (1980). They reported that an acceleration rate $\geq 1.25 \mathrm{x}$ was an effective and attainable rate for more than half of children who were assessed on a variety of skills (as reported by Liberty, 1975). 
Subjects put on the headphones before beginning and wore them throughout training. During training, only white noise was delivered through the headphones. Subjects were trained on each skill individually. Initially, a rule concerning each skill was presented on the computer screen along with examples (Appendix E). A mouse click on the Continue button at the bottom of the screen advanced the screen to a worksheet containing a series of items using that skill (Oddsson \& Chase, 1999). Subjects were required to choose their answer for each item from a set of 4 multiple-choice answers on the computer (Appendix F). The appropriate selection was made by clicking on the corresponding button, and once a selection was made, the answer could not be changed. Subjects were provided with scrap paper to work out problems, if necessary. After subjects completed their timing(s), feedback was provided regarding the accuracy of their answers. Incorrect answers were highlighted on each worksheet. If subjects failed to meet the terminal criteria or show improvement on a skill in 3 sessions (45 timings), they were to be dismissed from the study; however, it was not necessary to invoke this rule to dismiss any subjects. After every 15 timings, subjects were shown the rule and examples for each skill. No other corrective feedback was provided during the timing sessions.

Subjects continued the timings until the terminal rate aim was met. Subjects in both groups were required to perform at the terminal rate on at least 5 separate 1-min timings, although it was not necessary for these timings to occur consecutively. HR subjects received feedback on their performance after each timing. Subjects in the LR group were given feedback on their performance only after every $15^{\text {th }}$ timing. The same amount of feedback for a timing was given for correct and incorrect performance in the HR and LR groups. The difference between these two groups was in the rate of the feedback; HR subjects received feedback more frequently whereas LR subjects received feedback less frequently. 
Practice. To equate for practice effects on the timings, pairs of HR and LR subjects were yoked. The number of practice items each pair completed was based on the member who completed the most items during training. The number of items answered during those timings was calculated to determine which partner answered the most questions. The member with the fewer items completed was required to complete additional items to equate for number of practice items completed. If the HR subject had to complete additional items, feedback was delivered every min or after the subject completed the requisite number of practice items, whichever came first. If the LR subject was the one to complete additional practice items, feedback was delivered after 15 timings or after the subject completed the requisite number of practice items, whichever came first. In the most extreme case, the LR subject would have had to complete only 1 additional item and would receive feedback in $1 \mathrm{~s}$. This would result in the LR subject obtaining a reinforcement rate richer than once every $15 \mathrm{~min}$. The highest obtained ratio for an LR subject in the current study was approximately 1:5, which occurred for one subject on one rule, and it still exceeds the typical 1:4 ratio used in behavioral momentum studies (e.g., Dube \& Mcllvane, 2002; Nevin \& Grace, 1999).

Expert performance. Terminal rate aims were based on the performance of "experts" consisting of 5 math majors who completed the Exponent and Adduction pretests as well as the Retention tests with at least 90\% accuracy. Their performances on the Basic Skills pretest and timing worksheets determined the rate aims used in the study. For the Basic Skills pretest, experts were given each version of the pretest and were required to score with at least $90 \%$ accuracy on each version. To calculate rate per min, the total time in s was divided by 60 ; the number of items answered correctly then was divided by this quotient. The mean rate from the administrations that met the accuracy criterion was used to determine the rate criterion for 
subjects. Rate aims were determined separately for each Rule. For the timings worksheets, experts were instructed to answer as many questions as possible in $1 \mathrm{~min}$. The mean rates from the first 3 worksheets on which experts reached $90 \%$ accuracy were used as the rate aim for that Rule. Variability between and within experts' performances were considered to obtain representative expert performance criteria to use as rate aims. The aims that were used were 13 problems/min at $90 \%$ accuracy for Rule 1, and then 12 problems/min at $90 \%$ accuracy for Rules $2-5$.

Review worksheets. After reaching the rate aims on a skill, subjects were given a cumulative review worksheet similar to that used by Kim (2003). The review worksheet included items using each of the skills trained up to that point. There were 60 review items for each skill. To equate the number of items presented for each skill, the items were distributed over each of the 5 review sessions (Table 2). Prior to beginning the review worksheet, subjects were told that they would earn 2 cents for each correct answer. After subjects completed the review worksheet, the experimenter corrected the worksheet and provided corrective feedback. The experimenter reviewed the incorrect items with the subject and provided corrective feedback on how to calculate the correct answer. For example, if a subject incorrectly solved the problem $3^{2} h^{3} \cdot 3^{5} h^{2}$ $=9^{7} h^{5}$, the feedback was: "The coefficients in this problem are the same, so you don't multiply them. Instead, you keep the same coefficient and just add the exponents. So you should have $3^{7} h^{5}$,

Disruption tests. Tests were administered after subjects completed their training and review on a skill. No knowledge of results or corrective feedback was given during any testing condition. The first test, the Disruption test, was administered on the computer. The disruption tests consisted of 25 multiple-choice problems, similar to those on the training worksheets, and 
subjects could take as much time as needed to complete the items, although the time was recorded by the computer as a dependent measure. To test subjects for disruption, or resistance to distraction, a music recording of the experimenter reciting random coefficients, variables, and exponents was played through the headphones for Pair 1. When no disruption was observed, the audio distractor for all subsequent pairs was changed to a music recording with variations in intensity, volume, and rhythm. There were 5 different disruption tests, one test per rule (See Appendix G). Prior to the first Disruption test, the experimenter read the instructions with the subject to ensure that the subject understood the task and had no questions. For all Disruption tests, the screen had the following instructions:

This is the first test for this skill. You will earn 5 cents for each correct answer. Be careful when you click your answer, because once you click an answer, you cannot change it. There is no time limit for this test. There is scrap paper if you want to use it. Please make sure you keep the headphones on no matter what you hear through them. When you are finished, click the Finish button then let me know you are done.

Adduction tests. The second test was for Adduction, to determine whether subjects would combine individual skills without receiving specific training to do so. As with the Adduction pretest, there were 25 questions, with 8 items each combining 3 and 4 skills and 9 items combining all 5 skills. Prior to the first Adduction test, the experimenter read the instructions with the subject to ensure that the subject understood the task and had no questions. Time data were collected on the computer; subjects pressed a button to start the timer when they turned the test over and pressed a button to stop the timer when they were finished. White noise was played through the headphones during testing. The first page of all Adduction tests read: 
Here are some more questions for you to answer. You will earn 5 cents for each correct answer. You do not have to simplify your answers, so if the answer is $2^{8}$, you can leave it like that. There is no time limit for this test. There is scrap paper if you want to use it. Take your pen/pencil, make sure that your headphones are on. When you are ready to begin, press the Start button and turn the test over. When you are finished, press the Finished button and submit the test to the experimenter.

Retention tests. Approximately 2 weeks after completing the tests for fifth skill, subjects took written Retention tests. Subjects were given two 25 -question tests. The first 25 -item test was an Exponent post/retention test with 5 items per skill that was identical to the Exponent pretest. The second test was an Adduction test consisting of 25 items, including 8 items each for combinations of 3 and 4 skills, and 9 problem-solving items combining all 5 skills. The Retention tests had the following instructions:

This test uses the skills you learned before. Answer as many problems as you can. You will earn 5 cents for each correct answer. You do not have to simplify your answers, so if the answer is $2^{8}$, you can leave it like that. There is no time limit for this test. There is scrap paper if you want to use it. Take your pen/pencil, make sure that your headphones are on. When you are ready to begin, press the Start button and turn the test over. When you are finished, press the Finished button and submit the test to the experimenter.

\section{Interobserver agreement}

Interobserver agreement (IOA) was calculated for the review worksheets and all of the tests, except for the Distraction tests, which were automated. Approximately $30 \%$ of the worksheets and tests were re-graded for IOA purposes. Agreement percentages were calculated by dividing the total number of agreements by the sum of agreements and disagreements and 
Feedback and reinforcement 21

multiplying the answer by $100 \%$. IOA for the percentage correct on the worksheets and tests was $99 \%$, with a range of $92-100 \%$. IOA on time data was collected on approximately $20 \%$ of the tests, and correspondence of times within $\pm 10 \mathrm{~s}$ constituted an agreement. IOA for time data was $82 \%$.

Results

\section{Training}

To determine whether there were any differences between the groups on the number of timings required to reach criteria, a variety of data analysis techniques were used. First, overall comparisons were conducted to determine on a gross level which group was performing better on the measures. For training, there were 5 comparisons (one per rule) for each of 5 pairs of subjects, making a total of 25 comparative observations. Figure 1 shows the timings required to meet criteria for each rule by each pair of subjects. On 14 of 25 comparisons (56\%), the LR member of the pair required more timings to reach the terminal criteria, and on no comparisons did the pairs require the same number of timings to reach criteria. Pair-by-pair analyses also were conducted to determine which member generally performed better (i.e., on at least 3 of the 5 comparisons). For 3 of the 5 yoked pairs of subjects, the LR subject required more timings on most of the rules. Thus, the HR subjects reached criteria faster than their LR counterparts in most cases. Paired samples $t$-tests also were conducted for each rule to determine whether there were statistically significant differences between the groups in the number of timings required to reach criteria. The means, standard deviations, and $t$-values for each rule are provided in Table 3 . There were no significant differences between the groups. 
Feedback and reinforcement 22

\section{Cumulative Reviews}

Accuracy on the cumulative reviews was analyzed to determine whether any differences existed between the groups. The pair-by-pair comparisons are illustrated in Figure 2, and the means and standard deviations are reported in Table 4. On 17 of the 25 comparisons (68\%), the HR subject performed better than the LR counterpart, while both members of the pair performed equally well on 2 comparisons ( $8 \%$ ). For 4 of the 5 yoked pairs, the HR subject outperformed the LR counterpart on most of the reviews. Paired samples $t$-tests also were conducted on each review. There was a significant difference between the groups on Cumulative Review $3, t(4)=$ 4.256, $p=0.013$, with the HR group $(M=85.53, S D=6.45)$ outperforming the LR group $(M=$ $71.91, S D=12.53)$. There were no significant differences between the groups on any other cumulative reviews, however.

\section{Distraction Tests}

Accuracy and rate data were analyzed for the distraction tests. The pair-by-pair accuracy data are provided in Figure 3, and Table 5 lists the means and standard deviations for each comparison on the accuracy data. The HR subject performed more accurately on 11 of 25 (44\%) comparisons, and the pairs performed equally well on 6 of 25 (24\%) comparisons. The pair-bypair analysis indicated that the HR subject performed better on most of the measures for 3 of the 5 pairs. Additionally, one pair performed equally well on 3 of the 5 tests. Accuracy and rate data on the distraction tests were analyzed using paired-samples $t$-tests. However, none of the $t$-tests conducted on accuracy data yielded significant differences between the groups.

Rate data for the distraction tests are provided in Table 6 , and the pair-by-pair rate data are provided in Figure 4. The HR subject had a higher rate on 18 of the 25 (72\%) comparisons. Pair-by-pair analyses show that for 3 of 5 yoked pairs, the HR subject performed at a higher rate 
than the LR counterpart on most of the tests. As with the accuracy data, however, none of the $t$ tests revealed significant differences between the groups on rate of correct responding.

Finally, the distraction index was calculated for each test by determining the log response rate on the test relative to the baseline rate. The baseline rate was determined based on the mean response per min on the last 5 timings completed. Using the log response rate allows one to compare the proportional degrees of distraction regardless of differences in absolute rates. Figure 5 illustrates the pair-by-pair log data, and Table 7 lists the mean logarithms and standard deviations for each comparison on the distraction tests. The HR subject had a higher log rate on 15 of $25(60 \%)$ comparisons, and 3 of the 5 yoked pairs yielded higher log rates for the HR subject on most tests. Thus, The HR subject generally was less distracted than the LR counterpart during the distraction tests. It should be noted that the greatest discrepancy in log rates between the groups occurred on the distraction test for Rule 1, which probably provides the best barometer of distraction because the distraction task is novel at that point; subjects did not know that they would be given a distraction task, nor were they familiar with the distractor used. Paired-samples $t$-tests yielded no significant differences between the groups, however; as with the accuracy and rate data.

\section{Adduction Tests}

Accuracy and rate data were analyzed for the adduction tests. The HR subject performed more accurately than the LR counterpart on only 9 of 30 (30\%) comparisons (comparisons on the pretest were not included); however, neither participant answered any items correctly on 14 comparisons. Analyses of the yoked pairs showed that the HR subject performed better on most of the tests than the LR counterpart for 2 of the 5 pairs, and the LR subject outperformed the HR counterpart on 2 pairs. One pair did not answer any adduction problems correctly. These 
accuracy data are presented in Figure 6. Because the seven adduction tests were parallel, the accuracy and rate data were analyzed using a $2 \times 7$ mixed-measures analysis of variance (ANOVA), with a between-subjects factor of Group (HR, LR) and a within-subjects factor of Test (Pretest, Tests 1-5, Retention test). Because of the small Ns, violations of the assumption of sphericity are difficult to find, therefore the Greenhouse-Geisser correction was used. This correction adjusts the degrees of freedom downward and provides a very conservative basis for assessing the $F$ values. Table 8 lists the means and standard deviations for accuracy on the adduction tests. For the accuracy data, there was no significant interaction between the factors, nor was there a significant main effect of Group. There was, however, a significant main effect of Test, $F(1.887,15.095)=6.575, p=.010$. Pairwise comparisons using a Bonferroni correction for multiple comparisons yielded significant differences between the Pretest $(M=0.00, S D=$ $0.00)$ and Test $4(M=25.20, S D=32.93)$ and Test $5(M=27.60, S D=32.30)$, and the Retention test $(M=37.60, S D=35.34)$. The Retention test was also significantly different from Test $1(M=$ $0.40, S D=1.26)$, Test $2(M=0.00, S D=0.00)$, and Test $3(M=5.60, S D=9.47)$. Other significant differences were found comparing Test 1 with Tests 4 and 5, comparing Test 2 with Test 4 and Test 5, and comparing Tests 3 and 5. All comparisons were significant at the $p<0.05$ level. For the rate data, the HR subject outperformed the LR counterpart on 8 of the $30(25 \%)$ comparisons (comparisons on the pretest were not included); however, neither participant answered any items correctly on 13 comparisons (Figure 7). Analyses of the yoked pairs mirrored that of the accuracy data; the HR subjects outperformed their counterparts in 2 of the pairs, the LR subjects outperformed their counterparts in 2 of the pairs, and the other pair answered no questions correctly. The same statistical analysis used for the accuracy data was used for adduction rate data. Table 9 lists the means and standard deviations for the rates on the 
adduction tests. There was no significant interaction between Group and Test, nor was there a significant main effect for Group. There was, however, a significant main effect of Test, $F$ $(2.024,16.188)=4.256, p=.032$. Pairwise comparisons using a Bonferroni correction for multiple comparisons yielded significant differences between the Pretest $(M=0.00, S D=0.00)$ and Test $4(M=0.24, S D=0.28)$ and Test $5(M=0.29, S D=0.37)$, and the Retention test $(M=$ $0.36, S D=0.34)$. The Retention test was also significantly different from Test $1(M=0.30, S D=$ $0.11)$, Test $2(M=0.00, S D=0.00)$, and Test $4(M=0.24, S D=0.28)$. Other significant differences were found comparing Test 2 with Tests 4 and 5. All comparisons were significant at the $p<$ 0.05 level.

\section{Exponent tests}

Analyses were conducted on the accuracy and rate data for the exponent tests. Because the exponent pretest was administered 3 times, the best accuracy pretest score was used for the analyses. The HR subject did not outperform the LR counterpart on any of the exponent pretests. With 2 of the pairs, the LR subject outperformed the HR counterpart, and the other 3 yoked pairs performed equally (Figure 8). On the exponent retention test, however, the HR subject from each yoked pair performed more accurately than the LR counterpart. A 2 x 2 repeated-measures ANOVA was conducted with a between-subjects factor of Group (HR, LR) and a within-subjects factor of Test (Pretest, Retention). For the retention test analyses, the Greenhouse-Geisser correction was unnecessary because with only two levels of Test, the assumption of sphericity will always be met. Table 10 shows the means and standard deviations for accuracy on the exponent tests. There was a significant interaction between Group and Test, $F(1,8)=16.90, p=$ 0.003. Follow-up analyses revealed that the difference between the groups occurred on the retention test, $F(1,8)=7.744, p=0.02$, with the $\operatorname{HR}$ group $(M=90.40, S D=8.29)$ 
outperforming the LR group $(M=72.80, S D=11.45)$. Because the exponent posttest is also the retention test, it is reasonable to conclude that the HR group had higher gains and better retention of the exponent rules than the LR group.

The rate data on the pretests showed fairly equal performance, with the HR member of 2 yoked pairs performing faster, and the LR member of the other 2 pairs performing faster than his counterpart (Figure 9). The rate data for one pair could not be calculated because the data were corrupted before they were recorded and could not be recovered. On the retention test, the HR member of each pair performed faster than the LR counterpart. A 2 x 2 repeated-measures ANOVA also was used for the rate data on the exponent tests. Table 11 shows the means and standard deviations for rate on the exponent tests. There was no significant interaction between Group and Test, nor was there a significant main effect of Group. There was, however, a significant main effect of Test, $F(1,6)=28.49, p<0.01$, with rate of correct responding on the Retention test $(M=4.78, S D=2.64)$ exceeding the rates on the Pretest $(M=0.34, S D=0.13)$.

\section{Discussion}

The purpose of this study was to examine the role of differential rates of feedback and reinforcement on fluency outcomes while controlling for practice. Additionally, the current study broadened the scope of fluency research by examining multiple outcomes, namely retention, stability, and adduction. Based on the premise that RESAA outcomes involve behaviors that are resistant to change - that is, that the outcomes involve persistence of the learned behaviors despite temporal or other environmental disruptions - then higher rates of feedback and reinforcement should produce better RESAA performance, as demonstrated in resistance to change studies (e.g., Dube \& McIlvane, 2002; Lattal, 1989; Nevin, Mandell, \& Atak, 1983). 
The current study used a yoked group design, and statistical analyses were conducted in accordance with a group design. Unfortunately, the small $N$ and wide variability - both within and between groups - handicapped the robustness of the statistical tests. For instance, there were no significant differences found between the HR and LR groups on the number of timings required to reach criteria. On this measure, the lack of statistically significant findings can be attributed to the large within-group variability (e.g., for Rule 1, the HR timings required ranged from 24-126, and the LR group ranged from 61-133). Other measures, such as accuracy, rate, and $\log$ rate on the distraction tests, had very similar between-group means, which also could have contributed to the lack of statistically significant results. Many resistance to change studies that have used group designs have sidestepped variability problems by having large Ns (e.g., Pittenger \& Pavlik, 1998; Weatherly, Sauter, \& King, 2004). Usually, however, variability is not problematic in behavioral momentum studies because they are typically conducted using singlesubject designs, and subjects are compared only with themselves. With the restricted inclusion criteria and the yoking procedure of the current study, however, it was also appropriate to assume that the subjects in each pair were similar to each other and thus could be compared to one another directly (e.g., Podlesnik \& Chase, 2006), as with the overall and pair-by-pair analyses. These comparisons minimize the problems of the small $N$ and within-group variability and can provide a clearer representation of the differential effects of the HR and LR treatments. As such, the overall and pair-by-pair analyses are the ones that will be referenced in this discussion regarding the implications of these results.

\section{Training and cumulative review}

Based on the overall and pair-by-pair analyses, the HR subjects reached the terminal rate criteria faster than their LR counterparts. Thus, more frequent feedback and reinforcement is 
more efficient for training high-rate, high-accuracy behavior. This result could inform classroom practices regarding the expediency of providing performance feedback. If teachers could incorporate peer correction procedures or other methods that would provide immediate feedback and/or reinforcement for students, the amount of time required to master a skill could be decreased and teachers subsequently could allocate more time to enrichment activities.

The HR group also outperformed their LR counterparts on the cumulative review worksheets. These worksheets were used in this study to help facilitate adduction performance. Although students did not perform well on the adduction tests, it could be argued that cumulative review performance is a barometer for retention testing, because students are asked to perform skills that they learned previously, but have not recently performed. As such, perhaps the HR students' high achievement on the cumulative review is predictive of high achievement on the retention test. If so, cumulative review procedures may be useful not only for facilitating adduction (Kim, 2003; Mayfield \& Chase, 2002), but they also could help teachers identify areas that may require additional instruction or reminders prior to exams.

\section{Distraction and retention}

In addition to facilitating acquisition and performance on review worksheets, high rates of feedback and reinforcement produce better performance on both distraction and retention tests. Subjects in the HR group performed faster and more accurately on distraction tests than their counterparts who were exposed to lower consequence rates. Additionally, HR subjects have more stable behavior than their LR counterparts, as indicated by their higher log rates of responding on distraction tests. These results indicate that higher rates of consequences produce behavior that is more resistant to change, and thus responding remains stable despite environmental distractions. Similar results were found for the exponent retention test; all of the 
HR subjects outperformed their LR counterparts on both accuracy and rate measures. These results occurred despite the fact that none of the HR subjects outperformed their LR counterparts on the exponent pretest, indicating that not only do higher rates of feedback and reinforcement produce greater retention performance, but they also result in greater gains.

Although precision teachers would argue that RESAA outcomes are the product of training skills to occur at high rates with high accuracy (e.g., Lindsley, 1992), the current study shows mitigated effects of high-rate, high-accuracy responding when a lower rate of feedback and/or reinforcement is employed. Both the HR and LR subjects had to demonstrate mastery of the skills based on rate and accuracy criteria, yet the HR subjects consistently performed better on the distraction and retention tests. The differences between the groups are particularly evident on the distraction test for Rule 1, where the HR group had a log differential of +0.09 , and on the retention test, where the HR group outperformed the LR group by $20 \%$. If performance on these tasks were due solely to high-rate, high-accuracy learning, there should not have been consistent differences between the groups.

\section{Adduction}

Although the HR subjects outperformed their LR counterparts on both the stability and retention measures, results from the adduction tests showed fairly equal performance between the groups on both accuracy and rate measures. There was an extremely low incidence of adduction, however, as most subjects answered very few, if any, adduction items correctly. In response to failure to produce adduction in Walker (2005), cumulative review procedures were included in the current study that had previously been shown to facilitate adduction (Kim, 2003; Mayfield \& Chase, 2002), but those changes did not have the facilitative effect they did in previous studies. 
After the first pair that completed the study answered no adduction items correctly, subsequent changes were made to the administration of the adduction tests and to the presentation of Rule 5 (Order of Operations) in an attempt to facilitate adduction performance. Instructions for the adduction tests were changed to instruct subjects to show their work so they could receive partial credit for parts of the problem they completed correctly. It was thought that if students were provided an incentive to answer portions of the problems that they recognized, their performances would steadily improve as they learned more rules, resulting ultimately in the solution of the whole problem. Additionally, it was thought that repeated exposure to adduction tests without earning any money may result in learned helplessness (e.g., Sedek \& Kofta, 1990; Sergent \& Lambert, 1979). Thus, partial credit was given in an attempt to decrease the likelihood of learned helplessness. In addition to the changes in administration of the adduction tests, the presentation of the Rule 5 instructions was changed to show a more distinct step-by-step solution process in hopes of providing a model and prompt for solving adduction items. Despite these changes, subjects consistently failed to solve the adduction problems.

The failure of subjects to perform well on the adduction tests after mastering all of the individual rules including order of operations was surprising. Recall that according to the resistance to change theory presented in the introduction that adduction was conceptualized as requiring persistence of behaviors that have already come under the control of certain stimuli and persistence of behavioral variability in general. The results suggest that either discrimination of skills did not persist when the stimuli were presented in the form an adduction problem, or behavioral variation was not under discriminative control of these stimuli. Given that individual skills persisted on the distraction and retention tests, it seems likely that behavioral variation did not occur. This is particularly surprising given that in the current study the kind of behavioral 
variation necessary to solve these problems was addressed specifically and presumably mastered with the Order of Operations rule.

One possibility is that the behavior of solving these adduction problems needs to be directly trained. Anecdotally, after the retention tests, the subjects were shown how to solve an adduction problem step-by-step, and they subsequently were able to solve an adduction problem independently. This suggests that mastering the Order of Operations rule alone was insufficient to produce the behavior; subjects needed instruction about combining the Order of Operations rule with the other exponent rules to solve the problems. Mayfield and Glenn (in press) found that presenting students with a general problem-solving strategy, which was a verbal description of the Order of Operations rule (i.e., "work from the most inside thing to the most outside thing”), also was insufficient to produce problem-solving. Like the current study, Mayfield and Glenn trained the target skills until they were performed with high accuracy (although they did not have a rate criterion), but despite demonstrating mastery of component skills, problem solving did not emerge until more directed prompts were presented. Students did not reach the criterion for problem solving (at least 3 scores of $100 \%$ accuracy) until they were shown the correct starting point from which to begin applying the general problem-solving strategy. Even then, problem solving only occurred on simpler problems (i.e., those combining 2 component skills). Students reached criterion on more complex problem solving involving multiple combinations of the component skills only after transfer training, which involved adding and fading prompts to transfer control from stimuli associated with the component skill to stimuli in the problem solving tasks. It could be argued that students in the Mayfield and Glenn study did not have to demonstrate mastery of the Order of Operations rule; thus, these additional prompts may have been required so students could learn the general premise of Order of Operations, 
rather than the prompts being necessary for responding to the stimuli associated with the component tasks. The current study, however, required students to demonstrate mastery of the Order of Operations rule in addition to demonstrating mastery of the other component skills. Thus, students in the present study understood the Order of Operations rule as it applied to integers, but they were still unable to apply it to the problem solving items, which used polynomials. Nonetheless, one explanation for the lack of problem solving in the current study may be that there were insufficient prompts to cue students about where to start applying the Order of Operations rule and to respond to the stimuli from the component skills that were included in the problem solving tasks.

Research by Fuchs and colleagues (Fuchs, Prentice, Burch, Hamlett, Owen, Hosp, \& Jancek, 2003; Fuchs, Fuchs, Prentice, Burch, Hamlett, Owen, \& Schroeter, 2003) provides further support for the practice of direct transfer training to expand students' problem-solving strategies. Their research provided direct instruction for classifying problem types (i.e., problems that require the same rules for solution) regardless of changes to irrelevant stimuli (e.g., key words, additional questions requiring different operations). In these studies, students who received transfer training made more significant gains on a posttest measure than their control counterparts. Fuchs, Prentice, Burch, Hamlett, Owen, Hosp, et al., in particular, found that transfer training significantly improved performance compared to solution training alone. That is, students who were taught to recognize and solve problems with varied irrelevant stimuli outperformed those who were only taught how to solve the problems using one type of exemplar. Given that the Order of Operations rule in the current study was taught using only integers, the failure to vary the irrelevant stimuli (the integers) subsequently may have disrupted the solution training (Order of Operations). The results of Fuchs et al. and Mayfield and Glenn (in press) 
substantiate the anecdotal observations that students in the present study could solve the adduction problems after being shown how to do them and are consistent with the existing literature on transfer of training (e.g., Ellis, 1965).

Although transfer training can facilitate adduction performance, it could be argued that transfer of training procedures would result in reinforcement, thus disqualifying subsequent performances on similar items as "adduction." It may be possible, however, to create instructions that facilitate adduction, but are not considered direct training or transfer training. For instance, instructions could involve symbolic representations of numbers or operations, and subjects would have to list the order in which they would address each symbol. For example, in the problem $\sqrt[V]{\frac{(W \bullet X)^{Y}}{Z}}$, the subject would have to indicate that the operations, in order, are: multiplying $W$ and $X$, raising that quantity to the power of $Y$, dividing by $Z$, and finally taking the $W$ root. Alternatively, other arbitrary symbols (e.g., shapes) could be used in lieu of letters, since the letters may be confused as variables. Either way, the subjects do not actually have to do any computation, but rather they must only demonstrate that they know in which order the computations must occur.

This type of instruction might maintain the integrity of the adduction task, as subjects would be learning only how to determine the order in which operations must be addressed in a problem. Subjects would be given a variety of these problems, with different arrangements and relational positions of the operations. Such examples would increase the saliency of the relevant features (i.e., the relational positions of the operations), while minimizing the saliency of the irrelevant features (i.e., the numbers, variables, or other operations represented by the symbols). Carnine (1980) found that children learned a concept faster when the irrelevant features varied only minimally during training, although he speculated that such procedures may not be 
necessary or optimal for more sophisticated learners. It is possible that in the current study there was too much variation in the irrelevant features, which resulted in undergeneralization, or failure to respond to unfamiliar examples of the concept, in this case, Order of Operations (Carnine; Tennyson, Woolley, \& Merrill, 1972; Tiemann \& Markle, 1990).

Further support for the use of more generalized instruction is found in the instructional control literature (e.g., Bicard \& Neef, 2002; Joyce \& Chase, 1990; Lobo, 2005), which supports the use of strategic instructions over tactical instructions to facilitate problem solving. With strategic instructions, subjects are given a general problem-solving strategy or "rule of thumb" to apply to problems, whereas with tactical instructions, subjects are provided a specific pattern with which to solve a problem. Further support for using strategic over tactical instructions can be found in Kaminski, Sloutsky, and Heckler $(2005,2006)$. They examined the efficacy of using what they called "relevantly concrete" and "generic" instantiations to facilitate transfer to a novel situation. Relevantly concrete instantiations used familiar applications to teach the concept, whereas generic instantiations used abstract symbols to illustrate the concept. Thus, relevantly concrete instantiations, like tactical instructions, identify a specific response pattern to solve a specific type of problem, and generic instantiations, like strategic instructions, provide a more general response pattern that can be applied to a wide variety of problems. They found that training with relevantly concrete instantiations resulted in marginally better performance on the training tasks, but training generic instantiations resulted in far better performance on novel tasks. The argument is that because generic instantiations minimize competing, irrelevant features of the concept during training, transferring the concept to novel situations is easier. In the current study, the Order of Operations rule was presented using only integers, which may have served as more of a tactical or concrete instruction rather than a strategic or generic 
instruction, and the literature would suggest that this is not the optimal method of instruction for generalizing to novel situations. Instead, using a more general instruction like that of Mayfield and Glenn (in press) or the instructions using symbols proposed previously, presented in such a way as to allow testing for mastery, may be better to facilitate transfer to problem solving items. It is possible, though, that after such experience the problems used in this study would not be considered adduction; rather, they would be classified as application tasks.

\section{Future directions}

The current study has built upon the existing precision teaching literature by manipulating rate of reinforcement and feedback while maintaining high-rate, high-accuracy mastery performance criteria and equating for practice. As previously noted, however, overlearning could also have facilitative effects on performance. In the current study, HR subjects usually were the ones doing additional practice problems; thus, their superior performance may be attributed to overlearning. Because of practical considerations, the current study was unable to equate overlearning, but future research should address this issue. Additionally, the lack of adduction performance should be addressed. The current study highlights some of the potential problems with trying to establish conditions that produce adduction, such as undergeneralization and maintaining the integrity of the adduction task. Other variations of the procedure used herein should also be examined, such as using corrective feedback during training rather than just knowledge of results, varying the distractor used, and expanding the outcome measures to include endurance and application.

\section{Conclusion}

The results of the present study provide some support for the conceptualization of fluency outcomes in terms of resistance to change. The HR subjects acquired the skills faster than the LR 
subjects, were less distracted and performed faster under disruption conditions, and were faster and more accurate on the exponent retention tests. These results suggest that the high rate of reinforcement and feedback produced by precision teaching procedures may be the critical variables that produce fluency outcomes. The lack of consistent performance on adduction items, however, indicates that changes, such as incorporating transfer training and/or strategic instructions, might be necessary to provide the most effective means of facilitating problem solving. If the appropriate changes are made to facilitate adduction, the current results suggest that precision teaching procedures could provide an efficient method of classroom instruction that would address many teacher concerns (Education Week, 2006). Faster acquisition of component skills that results in less disruption and better retention would address the issue of demonstrating mastery of state standards on the standardized tests. Furthermore, faster acquisition would provide teachers with more time to focus on "higher order" tasks such as problem solving. If adduction training were provided, the extra time could be devoted to enrichment activities or to other subjects, such as social studies or music. 


\section{References}

Bicard, D. F., \& Neef, N. A. (2002). Effects of strategic versus tactical instructions on adaptation to changing contingencies in children with ADHD. Journal of Applied Behavior Analysis, 35 (4), 375-389.

Binder, C., Haughton, E. \& Van Eyk, D. (1990). Increasing endurance by building fluency: Precision teaching attention span. Teaching Exceptional Children, 22(3), 24-27.

Boniecki, K. A., \& Moore, S. (2003). Breaking the silence: Using a token economy to reinforce classroom participation. Teaching of Psychology, 30, 224 - 227.

Brunner, M., McLaughlin, T. F., \& Sweeney, W. J. (1993). Employing error drill and feedback to improve the legibility of manuscript and cursive handwriting. Journal of Precision Teaching, 11, 32-37.

Bullara, D. T., Kimball, J. W., \& Cooper, J. O. (1993). An assessment of beginning addition skills following three months without instruction or practice. Journal of Precision Teaching, 11, 11-16.

Carnine, D. (1980). Three procedures for presenting minimally different positive and negative instances. Journal of Educational Psychology, 72, 452-456.

Chiesa, M., \& Robertson, A. (2000). Precision Teaching and Fluency Training: making maths easier for pupils and teachers. Educational Psychology in Practice, 16(3), 297-310.

Driskell, J. E., Willis, R. P., \& Copper, C. (1992). Effect of overlearning on retention. Journal of Applied Psychology, 77, 615-622.

Doughty, S. S., Chase, P. N., \& O’Shields, E. M. (2004). Effects of rate building on fluent performance: A review and commentary. The Behavior Analyst, 27, 7-23.

Dube, W.V., \& McIlvane, W.J. (2002). Reinforcer rate and stimulus control in 
discrimination reversal learning. The Psychological Record, 52, 405-416.

Education Week (2006, February 8). Math and science education in the U. S. Chat transcript posted to http://www.edweek.org/chat/. Reprints may be requested from EPE Library, 6935 Arlington Road, Bethesda, MD 20814.

Ellis, H. C. (1965). The transfer of learning. Oxford, England: Macmillan.

Gilbert, T. F. (1957). Overlearning and the retention of meaningful prose. Journal of General Psychology, 56, 281-289.

Hartnedy, S. L., Mozzoni, M. P., \& Fahoum, Y. (2005). The effect of fluency training on math and reading skills in neuropsychiatric diagnosis children: A multiple baseline design. Behavioral Interventions, 20, 27-36.

Johnson, K., \& Layng, T. V. J. (1996). On terms and procedures: Fluency. Behavior Analyst, 19, 281-288.

Joyce, J. H., \& Chase, P. N. (1990). Effects of response variability on the sensitivity of rulegoverned behavior. Journal of the Experimental Analysis of Behavior, 54, 251-262.

Kaminski, J. A., Sloutsky, V. M., \& Heckler, A. F. (2005). Relevant concreteness and its effects on learning and transfer. In B. Bara, L. Barsalou \& M. Bucciarelli (Eds.), Proceedings of the XXVII Annual Conference of the Cognitive Science Society, USA, 1090-1095.

Kaminski, J. A., Sloutsky, V. M., \& Heckler, A. F. (2006). Do children need concrete instantiations to learn an abstract concept? In R. Sun \& N. Miyake (Eds.), Proceedings of the XXVIII Annual Conference of the Cognitive Science Society, USA, 411-416.

Kim, C. (2003). Response variability through cumulative review: Applications to mathematical problem solving. Unpublished doctoral dissertation, West Virginia University. 
Lattal, K.A. (1989). Contingencies on response rate and resistance to change. Learning and Motivation, 20, 191-203.

Lindsley, O. R. (1992). Precision teaching: Discoveries and effects. Journal of Applied Behavior Analysis, 25, 51-57.

Lobo, H. E. (2005). The instructional control of problem solving: Emergent relations and blending of repertoires. Unpublished master's thesis, West Virginia University.

Mayfield, K.H., \& Chase, P.N. (2002). The effects of cumulative practice on mathematics problem solving. Journal of Applied Behavior Analysis, 35, 105-123.

Mayfield, K. H., \& Glenn, I. M. (in press). An evaluation of interventions to facilitate algebra problem solving. Journal of Behavioral Education.

McGinnis, J. C., Friman, P. C., \& Carlyon, W. D. (1999). The effect of token rewards on "intrinsic" motivation for doing math. Journal of Applied Behavior Analysis, 32, 375379.

Miller, A. D., Hall, S. W., \& Heward, W. L. (1995). Effects of sequential 1-minute time trials with and without intertrial feedback and self-correlation on general and special education students' fluency with math facts. Journal of Behavioral Education, 5, 319-345.

Miller, L. K., \& Schneider, R. (1970). The use of a token system in project Head Start. Journal of Applied Behavior Analysis, 3, 191- 197.

Mullis, I. V. S., Martin, M. O., \& Foy, P. (2005). TIMSS 2003 International Mathematics Report. Chestnut Hill, MA: TIMSS \& PIRLS International Study Center, Lynch School of Education, Boston College.

Neef, N. A., Nelles, D. E., Iwata, B. A., \& Page, T. J. (2003). Analysis of precurrent skills in 
solving mathematics story problems. Journal of Applied Behavior Analysis, 36, 21-33.

Neuringer, A. (2003). Reinforced variation and selection. Animal Learning \& Behavior, 21, 8391.

Nevin, J. A., \& Grace, R. C. (1999). Does the context of reinforcement affect resistance to change? Journal of Experimental Psychology: Animal Behavior Processes, 25, 256-268.

Nevin, J.A., Mandell, C., \& Atak, J.R. (1983). The analysis of behavioral momentum. Journal of the Experimental Analysis of Behavior, 39, 49-59.

Oddsson, F., \& Chase, P. N. (1999, May). Fluency training with computerized voice recognition training methods. Presented at the Association for Behavior Analysis, Chicago, IL.

Pittenger, D. J., \& Pavlik, W. B. (1988). Analysis of the partial reinforcement effect in humans using absolute and relative comparisons of schedules. American Journal of Psychology, $101,1-14$.

Podlesnik, C. A., \& Chase, P. N. (2006). Sensitivity and strength: Effects of instructions on resistance to change. Psychological Record, 56, 303-320.

Rohrer, D., Taylor, K., Pashler, H., Wixted, J. T., \& Cepeda, N. J. (2005). The effect of overlearning on long-term retention. Applied Cognitive Psychology, 19, 361-374.

Sedek, G., \& Kofta, M. (1990). When cognitive exertion does not yield cognitive gain: Toward an informational explanation of learned helplessness. Journal of Personality and Social Psychology, 58, 729-743.

Sergent, J., \& Lambert, W. E. (1979). "Learned helplessness" or "learned incompetence?" Canadian Journal of Behavioural Science, 11, 257-273.

Shirley, M. J., \& Pennypacker, H. S. (1994). The effects of performance criteria on learning and retention of spelling words. Journal of Precision Teaching, 12, 73-86. 
Singer-Dudek, J., \& Greer, R. D. (2005). A long-term analysis of the relationship between fluency and the training and maintenance of complex math skills. The Psychological Record, 55, 361-376.

Skinner, B. F. (1969). Contingencies of reinforcement: A theoretical analysis. Englewood Cliffs, NJ: Prentice Hall.

Swain, J. C., \& McLaughlin, T. F. (1998). The effects of bonus contingencies in a classwide token program on math accuracy with middle-school students with behavioral disorders. Behavioral Interventions, 13, 11-19.

Tennyson, R. D., Woolley, F. R., \& Merrill, M. D. (1972). Exemplar and nonexemplar variables which produce correct concept classification behavior and specified classification errors. Journal of Educational Psychology, 2, 144-152.

Tiemann, P. W., \& Markle, S. M. (1990). Analyzing instructional content: A guide to instruction and evaluation. $\left(4^{\text {th }}\right.$ ed.). Champaign, IL: Stipes.

Van Houten, R., \& Thompson, C. (1976). The effects of explicit timing on math performance. Journal of Applied Behavior Analysis, 9, 227-230.

Walker, V. L. (2005). The role of reinforcement rate on fluency. Unpublished master's thesis, West Virginia University.

Weatherly, J. N., Sauter, J. M., King, B. M. (2004). The "big win" and resistance to extinction when gambling. Journal of Psychology, 138, 495-504.

White, O.R., \& Haring, N.G. (1980). Exceptional Teaching. Columbus, OH: Bell \& Howell Company.

Wolf, M. M., Giles, D. K., \& Hall, R. V. (1968). Experiments with token reinforcement in a remedial classroom. Behaviour Research and Therapy, 6, 51-64. 
Feedback and reinforcement 42

Young, K. R., West, R. P., \& Crawford, A. (1985). The acquisition and maintenance of reading skills by intellectually handicapped deaf students. Journal of Precision Teaching, 5, 7386. 
Table 1. Training and testing sequence

Step 1 Pretesting

Basic Pretest

Exponent Pretest

Adduction Pretest

Step 2 Pretraining

Step 3 Training on Skill 1

Step 4 Testing

Disruption for Skill 1

Adduction

Step 5 Training and Testing on Skills 2-5 (repeat steps 2 and 3 for each skill)

Step 6 Retention Tests

Note: The retention tests occurred approximately two weeks after the testing sequence was completed for the fifth skill. 
Feedback and reinforcement 44

Table 2. Number of skill items distributed over cumulative practice review worksheets.

\begin{tabular}{cccccc}
\hline Review Worksheet & Skill 1 & Skill 2 & Skill 3 & Skill 4 & Skill 5 \\
\hline 1 & 12 & -- & -- & -- & -- \\
2 & 12 & 15 & -- & -- & -- \\
3 & 12 & 15 & 20 & -- & -- \\
4 & 12 & 15 & 20 & 30 & -- \\
5 & 12 & 15 & 20 & 30 & 60 \\
\hline Total items & 60 & 60 & 60 & 60 & 60 \\
\hline
\end{tabular}


Feedback and reinforcement 45

Table 3. Mean number of timings required to reach terminal criteria for each rule by group.

\begin{tabular}{lllllll}
\hline Rule & Group & N & Mean & SD & $t$ & Sig. \\
\hline 1 & HR & 5 & 68.00 & 41.97 & -1.384 & .239 \\
& LR & 5 & 96.80 & 33.39 & & \\
2 & & & & & & \\
& HR & 5 & 17.40 & 8.50 & -0.178 & .867 \\
& LR & 5 & 18.80 & 13.65 & & \\
3 & HR & 5 & 21.60 & 12.46 & -0.558 & .606 \\
& LR & 5 & 28.60 & 20.23 & & \\
& & & & & & \\
4 & HR & 5 & 16.00 & 8.80 & 2.021 & .113 \\
& LR & 5 & 9.40 & 3.36 & & \\
5 & & & & & & \\
& HR & 5 & 44.60 & 22.50 & -2.280 & .085 \\
& LR & 5 & 97.00 & 37.66 & & \\
\hline
\end{tabular}


Feedback and reinforcement 46

Table 4. Mean percentage correct on cumulative reviews by group.

\begin{tabular}{lllllll}
\hline Review & Group & N & Mean & SD & $t$ & Sig. \\
\hline 1 & HR & 5 & 73.33 & 37.91 & 0.534 & 0.621 \\
& LR & 5 & 71.67 & 37.55 & & \\
2 & HR & 5 & 82.96 & 21.05 & 0.649 & 0.552 \\
& LR & 5 & 77.77 & 24.14 & & \\
& & & & & & \\
3 & HR & 5 & 85.53 & 6.45 & 4.256 & 0.013 \\
& LR & 5 & 71.91 & 12.53 & & \\
4 & HR & 5 & 81.04 & 10.97 & -0.550 & 0.611 \\
& LR & 5 & 83.64 & 6.13 & & \\
& & & & & & \\
5 & HR & 5 & 85.58 & 13.37 & 1.419 & 0.251 \\
& LR & 5 & 68.43 & 11.71 & & \\
\hline
\end{tabular}

Note: The Review number indicates the rule after which the review was given, e.g., Review 1 was given after completing Rule 1, Review 2 was given after completing Rule 2, etc. 
Table 5. Means and standard deviations for percentage correct on distraction tests by group.

\begin{tabular}{lllllll}
\hline Test & Group & N & Mean & SD & $t$ & Sig. \\
\hline 1 & HR & 5 & 97.60 & 2.19 & 1.124 & 0.324 \\
& LR & 5 & 92.80 & 8.67 & & \\
2 & & & & & & \\
& HR & 5 & 96.00 & 2.83 & 1.809 & 0.145 \\
& LR & 5 & 91.20 & 3.35 & & \\
3 & HR & 5 & 96.80 & 5.22 & 0.000 & 1.000 \\
& LR & 5 & 96.80 & 5.22 & & \\
4 & & & & & & \\
& HR & 5 & 97.60 & 2.19 & 0.000 & 1.000 \\
& LR & 5 & 97.60 & 5.37 & & \\
5 & & & & & & \\
& HR & 5 & 88.00 & 18.55 & 0.639 & 0.557 \\
& LR & 5 & 81.60 & 11.87 & & \\
\hline
\end{tabular}

Note: The test number corresponds to the Rule covered by the distraction test; e.g., Test 1 covers

Rule 1, Test 2 covers Rule 2, etc. 
Feedback and reinforcement 48

Table 6. Means and standard deviations for rate of correct responses per min on distraction tests by group.

\begin{tabular}{lllllll}
\hline Test & Group & $\mathrm{N}$ & Mean & SD & $t$ & Sig. \\
\hline 1 & HR & 5 & 8.77 & 1.99 & 1.186 & 0.301 \\
& LR & 5 & 7.05 & 1.79 & & \\
2 & HR & 5 & 9.68 & 2.95 & 0.690 & 0.528 \\
& LR & 5 & 8.62 & 1.50 & & \\
& & & & & & \\
3 & HR & 5 & 7.90 & 2.47 & 1.785 & 0.149 \\
& LR & 5 & 6.40 & 1.24 & & \\
4 & HR & 5 & 11.45 & 1.02 & 0.227 & 0.831 \\
& LR & 5 & 11.22 & 2.37 & & \\
& & & & & & \\
5 & HR & 5 & 6.53 & 3.43 & 1.337 & 0.252 \\
& LR & 5 & 3.89 & 1.10 & & \\
\hline
\end{tabular}

Note: The test number corresponds to the Rule covered by the distraction test; e.g., Test 1 covers Rule 1, Test 2 covers Rule 2, etc. 
Feedback and reinforcement 49

Table 7. Means and standard deviations for log rate of correct responding per min on distraction tests by group.

\begin{tabular}{lllllll}
\hline Test & Group & N & Mean & SD & $t$ & Sig. \\
\hline 1 & HR & 5 & 0.84 & 0.06 & 1.971 & 0.120 \\
& LR & 5 & 0.75 & 0.08 & & \\
2 & HR & 5 & 0.85 & 0.11 & 0.290 & 0.786 \\
& LR & 5 & 0.83 & 0.07 & & \\
& & & & & & \\
3 & HR & 5 & 0.75 & 0.14 & -0.547 & 0.614 \\
& LR & 5 & 0.77 & 0.11 & & \\
4 & HR & 5 & 0.97 & 0.14 & 0.420 & 0.696 \\
& LR & 5 & 0.94 & 0.07 & & \\
& & & & & & \\
5 & HR & 4 & 0.67 & 0.08 & 0.143 & 0.893 \\
& LR & 4 & 0.65 & 0.23 & & \\
\hline
\end{tabular}

Note: The test number corresponds to the Rule covered by the distraction test; e.g., Test 1 covers Rule 1, Test 2 covers Rule 2, etc. 
Feedback and reinforcement 50

Table 8. Means and standard deviations for accuracy on adduction tests by group.

\begin{tabular}{|c|c|c|c|c|}
\hline Test & Group & $\mathrm{N}$ & Mean & $\mathrm{SD}$ \\
\hline \multirow[t]{2}{*}{ Pretest } & HR & 5 & 0.00 & 0.00 \\
\hline & LR & 5 & 0.00 & 0.00 \\
\hline \multirow[t]{2}{*}{1} & HR & 5 & 0.00 & 0.00 \\
\hline & LR & 5 & 0.80 & 1.79 \\
\hline \multirow[t]{2}{*}{2} & HR & 5 & 0.00 & 0.00 \\
\hline & LR & 5 & 0.00 & 0.00 \\
\hline \multirow[t]{2}{*}{3} & HR & 5 & 7.20 & 10.73 \\
\hline & LR & 5 & 4.00 & 8.94 \\
\hline \multirow[t]{2}{*}{4} & HR & 5 & 21.60 & 37.48 \\
\hline & LR & 5 & 28.80 & 31.67 \\
\hline \multirow[t]{2}{*}{5} & HR & 5 & 39.20 & 37.99 \\
\hline & LR & 5 & 16.00 & 23.83 \\
\hline \multirow[t]{2}{*}{ Retention } & HR & 5 & 40.80 & 37.14 \\
\hline & LR & 5 & 34.40 & 37.48 \\
\hline
\end{tabular}

Note: The test number corresponds to the Rule covered by the distraction test; e.g., Test 1 covers Rule 1, Test 2 covers Rule 2, etc. 
Feedback and reinforcement 51

Table 9. Means and standard deviations for rate of correct responding on adduction tests by

group.

\begin{tabular}{|c|c|c|c|c|}
\hline Test & Group & $\mathrm{N}$ & Mean & SD \\
\hline \multirow[t]{2}{*}{ Pretest } & HR & 5 & 0.00 & 0.00 \\
\hline & LR & 5 & 0.00 & 0.00 \\
\hline \multirow[t]{2}{*}{1} & HR & 5 & 0.00 & 0.00 \\
\hline & LR & 5 & 0.07 & 0.15 \\
\hline \multirow[t]{2}{*}{2} & HR & 5 & 0.00 & 0.00 \\
\hline & LR & 5 & 0.00 & 0.00 \\
\hline \multirow[t]{2}{*}{3} & HR & 5 & 0.22 & 0.43 \\
\hline & LR & 5 & 0.13 & 0.29 \\
\hline \multirow[t]{2}{*}{4} & HR & 5 & 0.27 & 0.36 \\
\hline & LR & 5 & 0.20 & 0.20 \\
\hline \multirow[t]{2}{*}{5} & HR & 5 & 0.38 & 0.48 \\
\hline & LR & 5 & 0.19 & 0.25 \\
\hline \multirow[t]{2}{*}{ Retention } & HR & 5 & 0.43 & 0.41 \\
\hline & LR & 5 & 0.28 & 0.29 \\
\hline
\end{tabular}

Note: The test number corresponds to the Rule covered by the distraction test; e.g., Test 1 covers

Rule 1, Test 2 covers Rule 2, etc. 
Feedback and reinforcement 52

Table 10. Means and standard deviations for accuracy on the exponent tests.

\begin{tabular}{lllll}
\hline Test & Group & N & Mean & SD \\
\hline Pretest & HR & 5 & 16.80 & 7.69 \\
& LR & 5 & 20.00 & 5.66 \\
Retention & & & & \\
& HR & 5 & 90.40 & 8.29 \\
& LR & 5 & 72.80 & 11.45 \\
\hline
\end{tabular}


Feedback and reinforcement 53

Table 11. Means and standard deviations for rate of correct responses per min on the exponent tests.

\begin{tabular}{lllll}
\hline Test & Group & $\mathrm{N}$ & Mean & SD \\
\hline Pretest & HR & 4 & 0.36 & 0.12 \\
& LR & 4 & 0.32 & 0.16 \\
\multirow{2}{*}{ Retention } & & & & \\
& HR & 4 & 6.09 & 3.13 \\
& LR & 4 & 3.47 & 1.37 \\
\hline
\end{tabular}




\section{Figure Captions}

Figure 1. Number of timings required by each yoked pair to reach terminal criteria by rule.

Figure 2. Percent correct on cumulative review worksheets by rule for each yoked pair.

Figure 3. Percent correct on distraction tests by rule for each yoked pair.

Figure 4. Rate of correct responding on distraction tests by rule for each yoked pair.

Figure 5. Log rate of correct responding on distraction tests by rule for each yoked pair.

Figure 6. Percent correct on adduction tests by rule for each yoked pair.

Figure 7. Rate of correct responding on adduction tests by rule for each yoked pair.

Figure 8. Percent correct on exponent pretest and retention test for each yoked pair.

Figure 9. Rate of correct responding on exponent pretest and retention test for each yoked pair. 

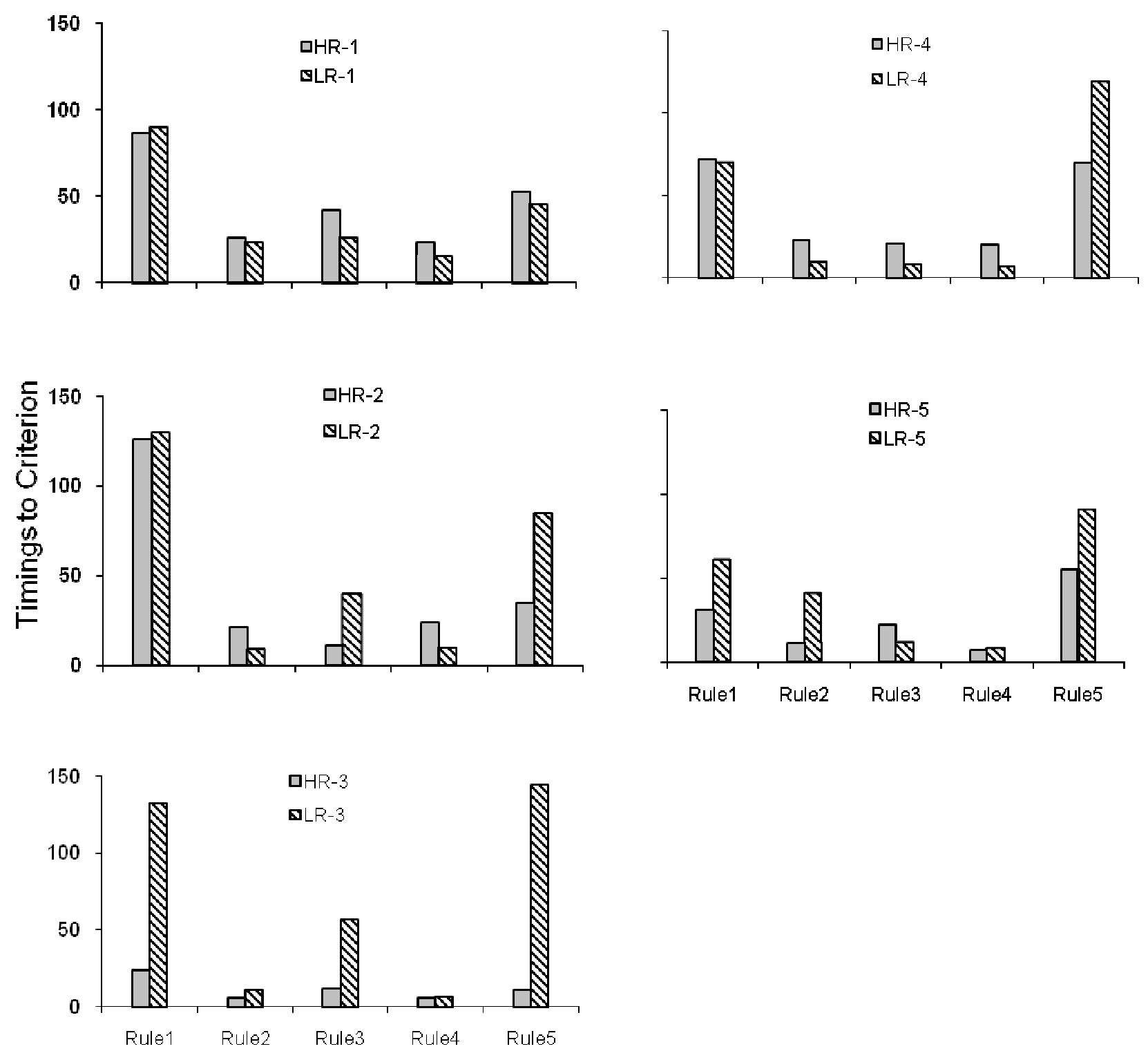

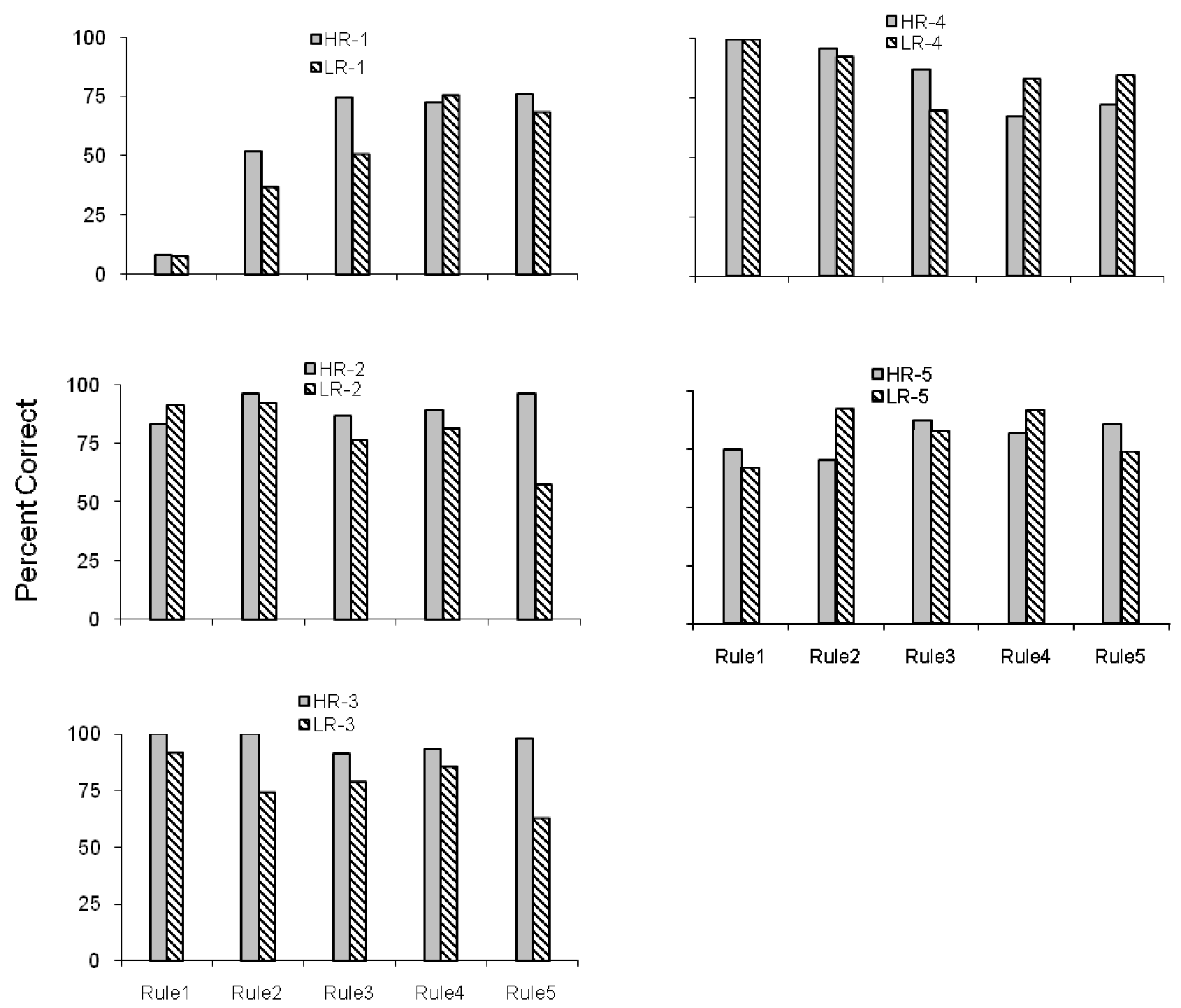
Feedback and reinforcement 57
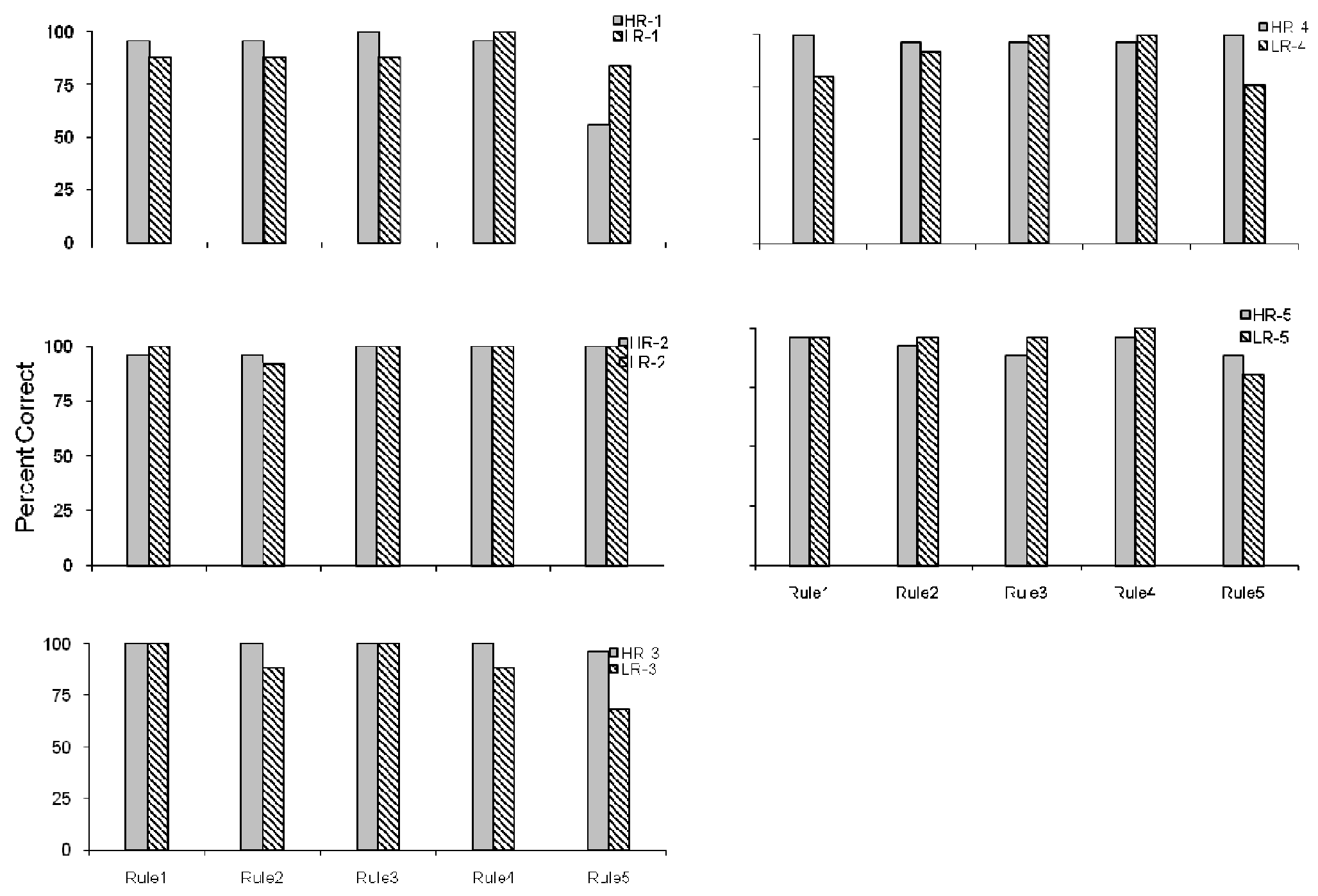

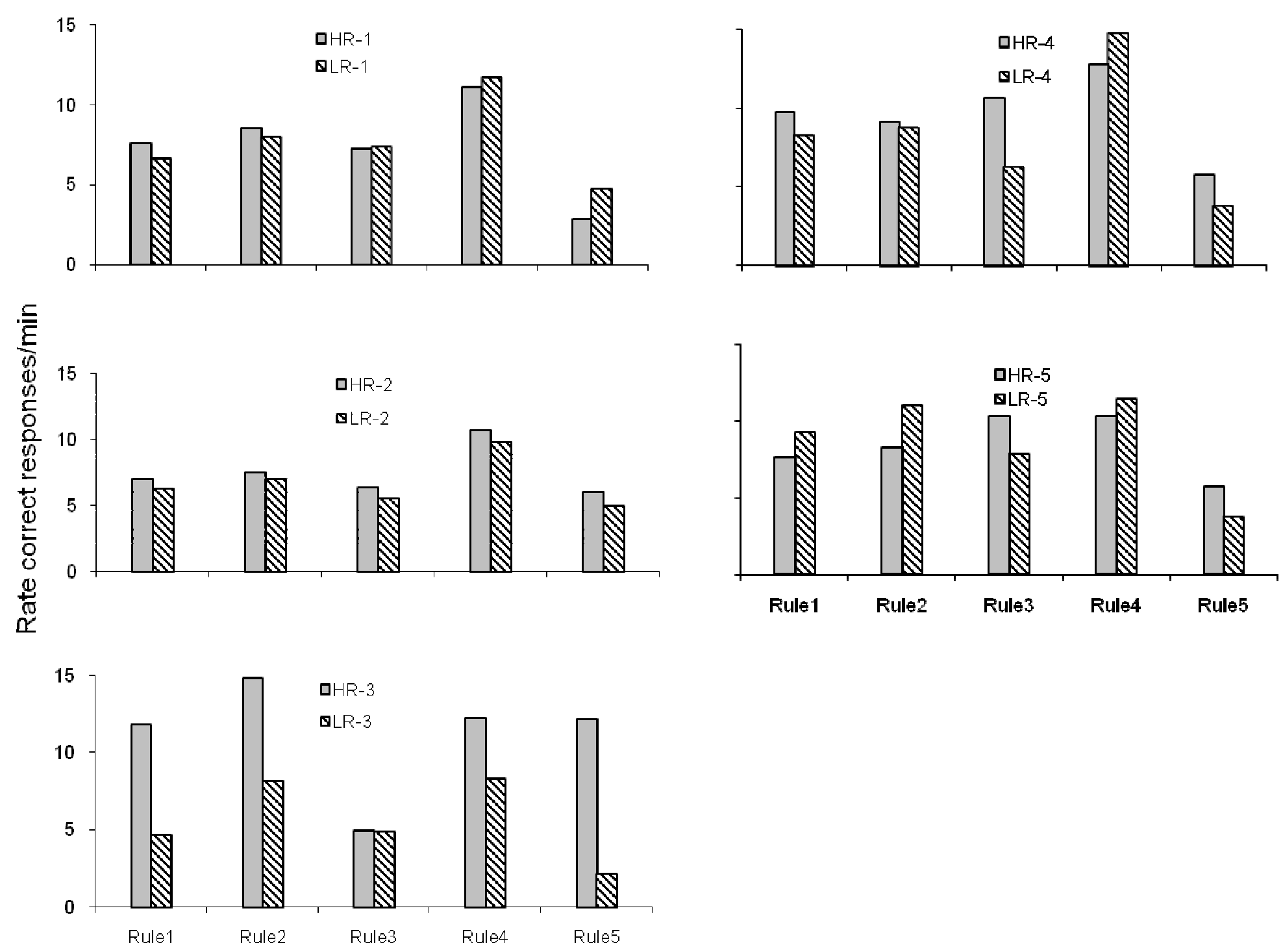


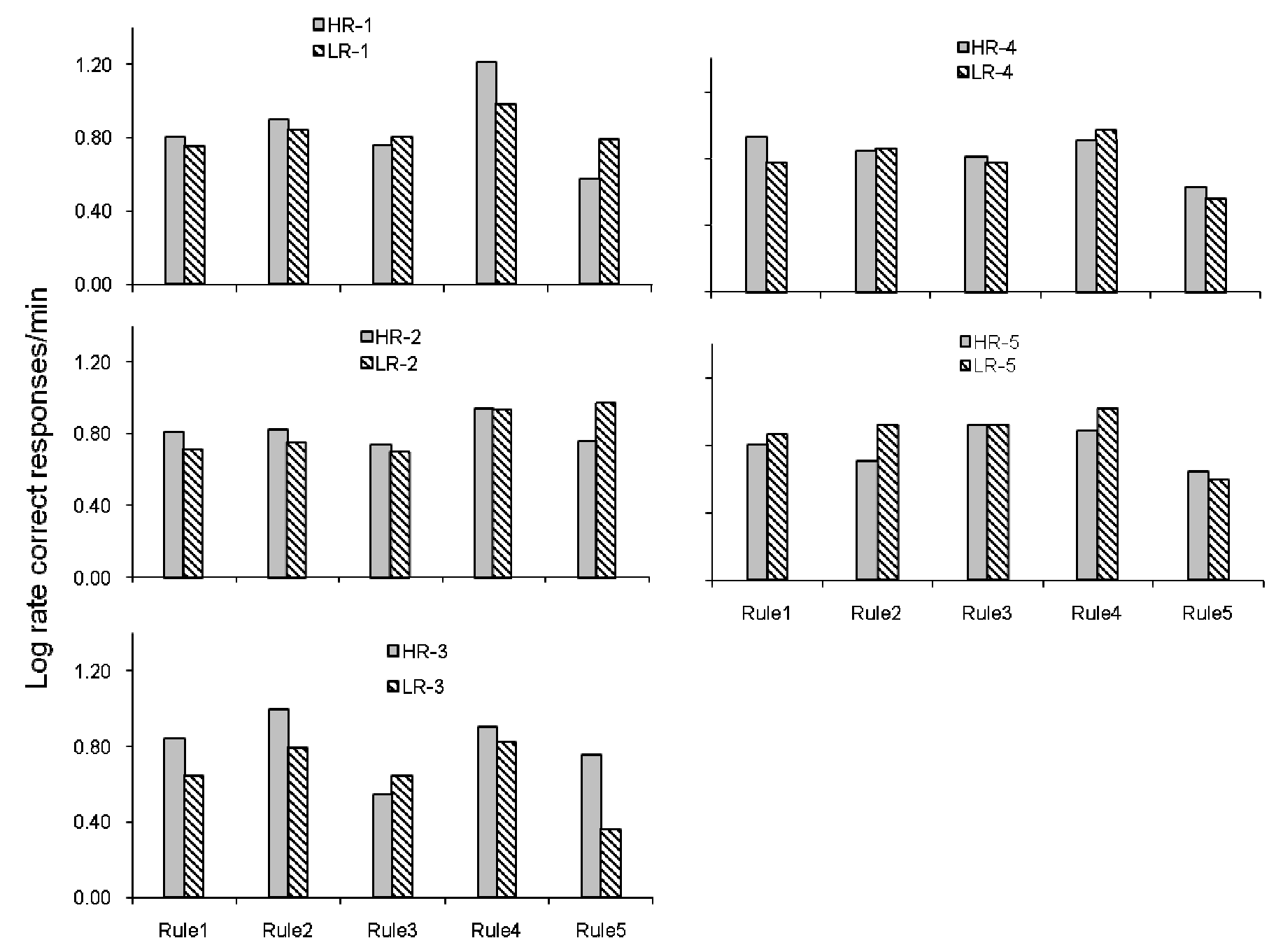



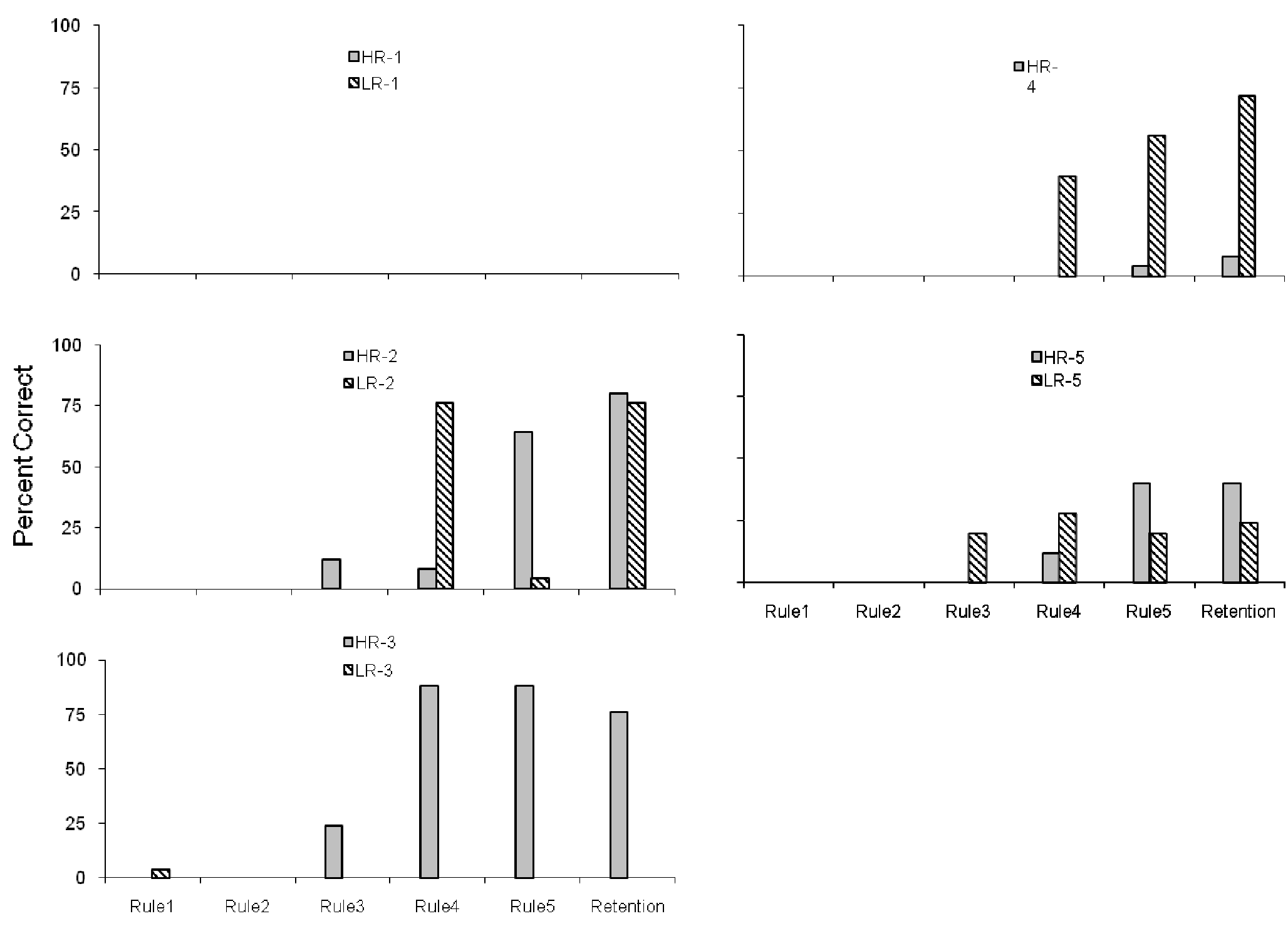

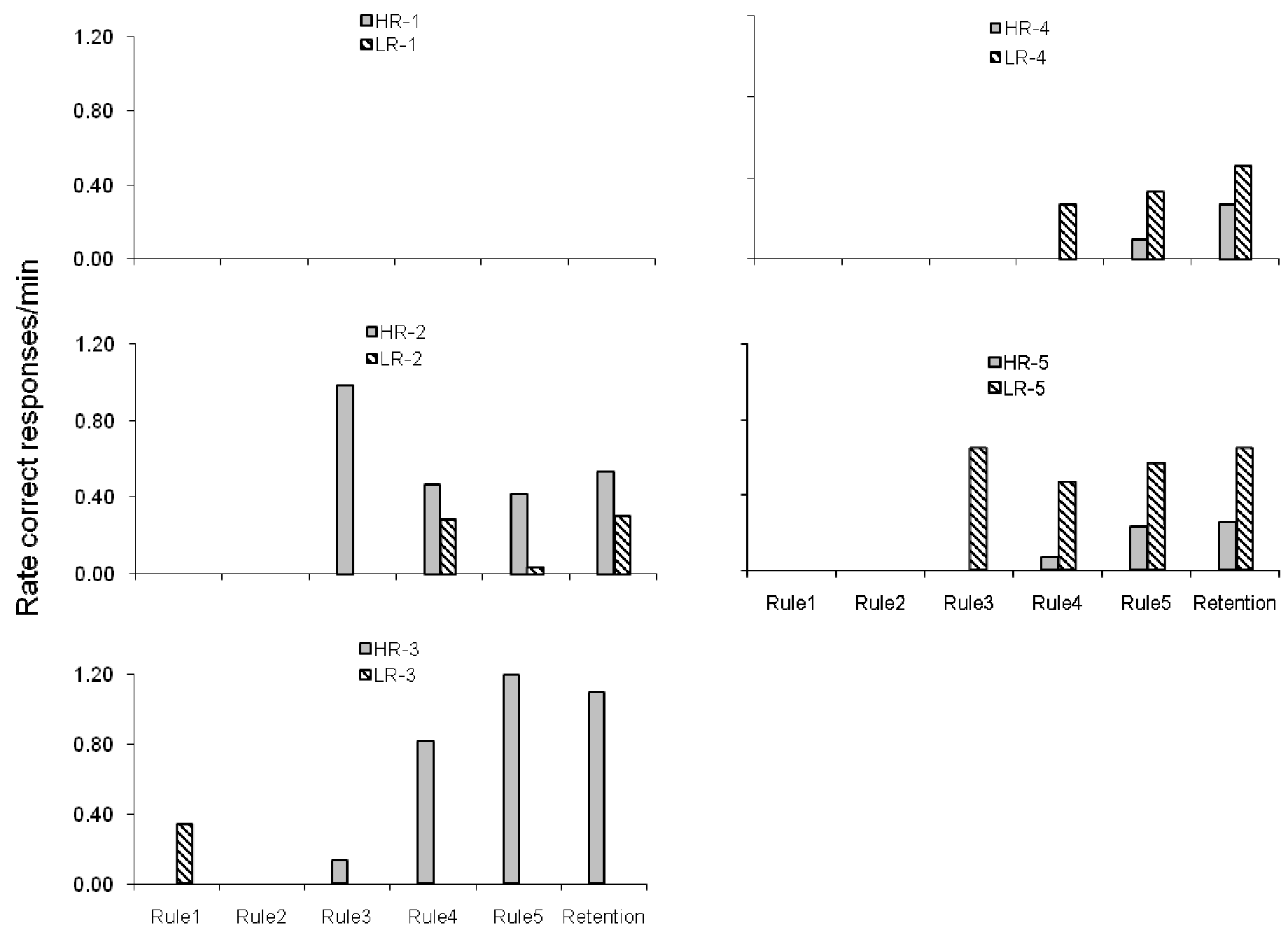


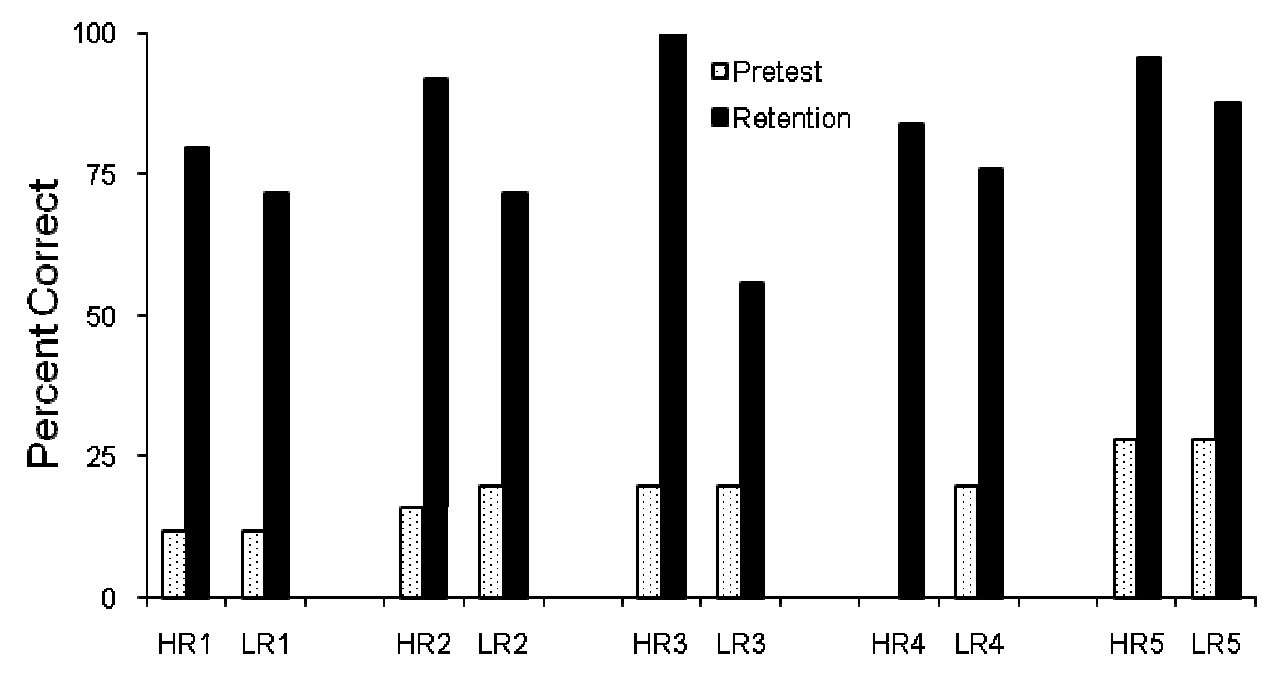




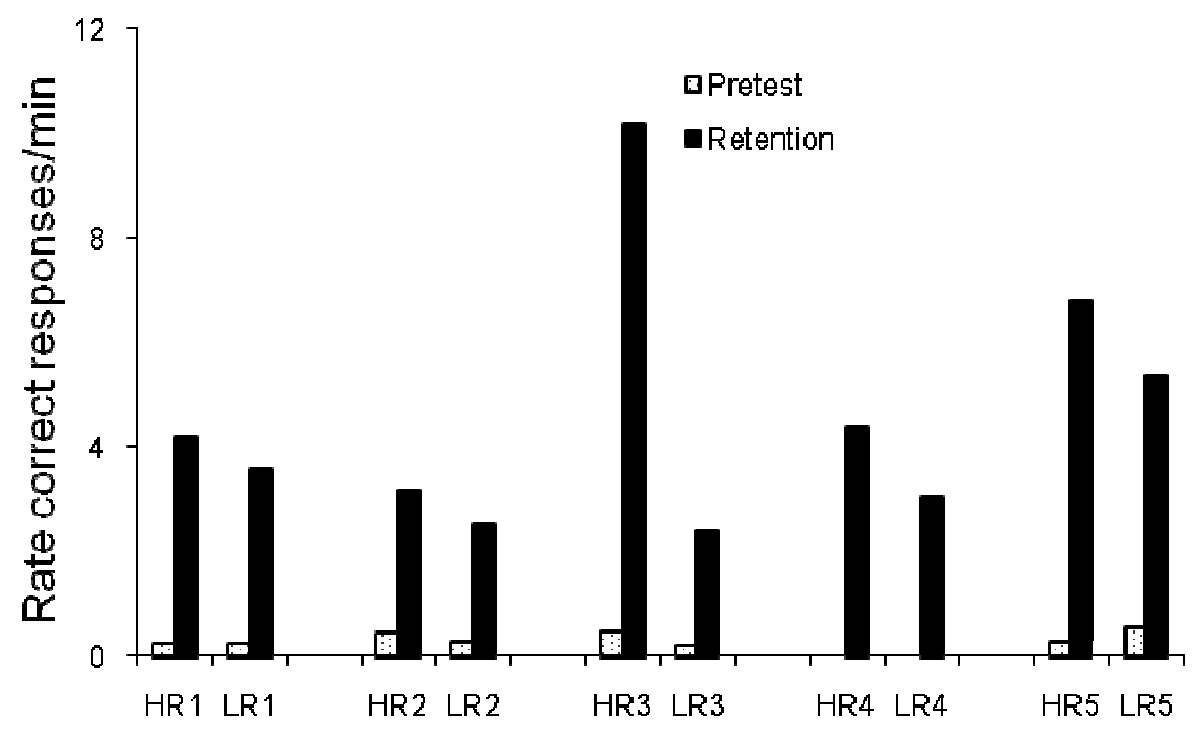


Feedback and reinforcement 64

\section{Appendix A: Cover letter, Informed Consent Form, and Assent Form}

\section{Dear Parent and/or Guardian:}

My name is Vennessa Walker, and I am a graduate student at West Virginia University. I am preparing to conduct my doctoral dissertation project, and I would like to ask you to allow your child to participate in my project. My dissertation examines the effects of teacher feedback and rewards on learning math skills, specifically, methods for adding, subtracting, multiplying, and dividing exponents. These skills are listed in West Virginia's Content Objectives and Standards at the $7^{\text {th }}$-grade level. The skills needed to learn the rules for exponents are the basic arithmetic skills that your child should already have learned.

The program I plan to use to teach these skills involves a series of computer-based lessons. Specifically, the lessons will teach your child to complete exponent problems quickly and accurately. Your child will then be tested on whether he/she can use these exponent skills on other tasks such as problem solving questions. In addition to learning more about math, your child can also earn gift certificates for local businesses or movie theatres. Your child may take anywhere from 2-4 weeks to learn the math skills because the program is self-paced.

I would greatly appreciate it if you would allow your child to participate in this study. I would be happy to answer any questions you may have. You may reach me via email at vwalker1@ mix.wvu.edu or by phone at (304) 685-7477. You may also contact my faculty supervisor, Dr. Phil Chase, at pchase@wvu.edu or by phone at (304) 293-2001 x31626. I have included an informed consent form detailing the study. If you agree to allow your child to participate, please sign and return the consent form in the envelope provided. Be sure to include a phone number where I can contact you to arrange meeting times. If you prefer to be contacted via email, please include your email address. Thank you for your consideration, and I look forward to hearing from you and working with your child.

Sincerely,

Vennessa L. Walker, M.S. SREB Doctoral Scholar 


\section{Parental or Guardian Consent and Information Form}

Title: Effects of reinforcement rate on novel responding

\section{Introduction}

$\mathrm{I}$, have been asked to allow my child, to participate in this study, which has been explained to me by Vennessa L. Walker, M.S., or one of her research assistants. This study is being conducted by Vennessa L. Walker in the Department of Psychology at West Virginia University.

This research is being conducted to fulfill the requirements for a doctoral dissertation in the Department of Psychology at West Virginia University, under the supervision of Professor Philip N. Chase.

\section{Purposes}

The purpose of this study is to evaluate effects of feedback and other reinforcers on learning mathematics skills. WVU plans to enroll approximately 32 subjects from all sites.

\section{Description of Procedures}

This study will be conducted in Room 2127 in the Department of Psychology at West Virginia University or at your child's school, depending upon availability. Your child will be asked to complete a set of diagnostic tests to determine his or her eligibility for the study. If selected for the study, your child will be randomly assigned to a group. Your child will be trained in a series of mathematical skills, using a computer to facilitate learning. After reaching a mastery criterion on a skill, your child will undergo a series of tests before beginning training on the next skill. Two weeks after completing the tests for the last skill, your child will take a retention test.

Participation in this project will take approximately 2 hours per day, 5 days a week, for 2 weeks. If your child does not meet the eligibility requirements or training criteria, he/she will be excused from the study. If your child fails to attend a scheduled session and the investigator is not notified beforehand, your child may be excused from the study. Your child will learn the math skills at his/her own pace; thus the length of the study may vary from approximately 2 weeks to 4 weeks.

\section{Risks and Discomforts}


There are no known or expected risks from participating in this study, except for mild frustration sometimes associated with performance on tests.

\section{Alternatives and Benefits}

Your child does not have to participate in this study. You may elect not to supplement your child's math training through this program or may use alternative math programs. Your child may earn gift certificates based on their performance, up to $\$ 50.00$. If your child chooses not to complete the study or if your child is excused from the study prior to its completion, he/she will forfeit any money earned towards the gift certificate(s). This study also may benefit your child by improving his or her mathematics skills.

\section{Contact Persons}

For more information about this research, you may contact Vennessa Walker at (304) 685-7477, or her supervisor, Dr. Philip N. Chase at (304) 293-2001 x 31626. For information regarding rights as a research subject, you may contact the Executive Secretary of the Institutional Review Board at (304) 293-7073.

\section{Confidentiality}

Any information about your child obtained as a result of participation in this research will be kept as confidential as legally possible. Your child's research records and test results, just like hospital records, may be subpoenaed by court order or may be inspected by the study sponsor or federal regulatory authorities without your additional consent. Audiotapes or videotapes will be kept locked up and will be destroyed as soon as possible after the research is finished. In any publications that result from this research, neither your child's name nor any information from which your child might be identified will be published without your consent.

\section{Voluntary Participation}

Participation in this study is voluntary. You are free to withdraw your child from this study at any time. Refusal to participate or withdrawal will involve no penalty or loss of benefits and will not affect any of your child's grades or class standing. You hereby acknowledge that you have been given the opportunity to ask questions about the research and have received answers concerning areas you did not understand. In the event new information becomes available that may affect your willingness to allow your child to continue to participate in the study, that information will be given to you so you may make an informed decision about your child's participation. Upon signing this form, you will receive a copy.

I willingly consent to allow my child to participate in this study. 
Feedback and reinforcement 67

Signature of Parent/Guardian

Child's Name (printed)

Signature of Investigator or Investigator's Representative $\overline{\text { Contact information }} \overline{\text { Date }}$

Date 


\section{Participant Assent Form}

Title: Effects of reinforcement rate on novel responding

\section{Introduction}

You, have been asked to be in this research study, which has been explained to you by Vennessa L. Walker or one of her research assistants.

\section{Purposes of the Study}

You have been told that the purpose of this study is to learn more about how people learn math.

\section{Description of Procedures}

This study will be done on campus at West Virginia University or at your school.

You will take some tests to see what you already know about math.

You will learn some math skills.

You will be tested on the skills you learn.

It will take about two hours each day. You do not have to answer all of the questions. About two weeks after you learn the last skill, you will come back and take one last test.

\section{Discomforts}

Some of the questions will be hard and you may not like trying to answer them.

\section{Benefits}

This study may help you learn more math. You may also earn gift certificates for stores in the mall or movie theater.

\section{Confidentiality}

We promise that anything we learn about you in this study will be kept as secret as possible. 


\section{Voluntary Participation}

You do not have to do this. No one will be mad at you if you decide not to do this or if you decide to quit.

You have been allowed to ask questions about the research, and all of your questions were answered.

I willingly agree to be in this research.

Participant's Signature

Printed Name

Date

Time

The child has had the opportunity to have questions addressed. The child willingly agrees to be in the study.

Signature of Investigator or Co-Investigator

Printed Name

Date

Time 
Appendix B: Sample screen from Basic Skills pretest

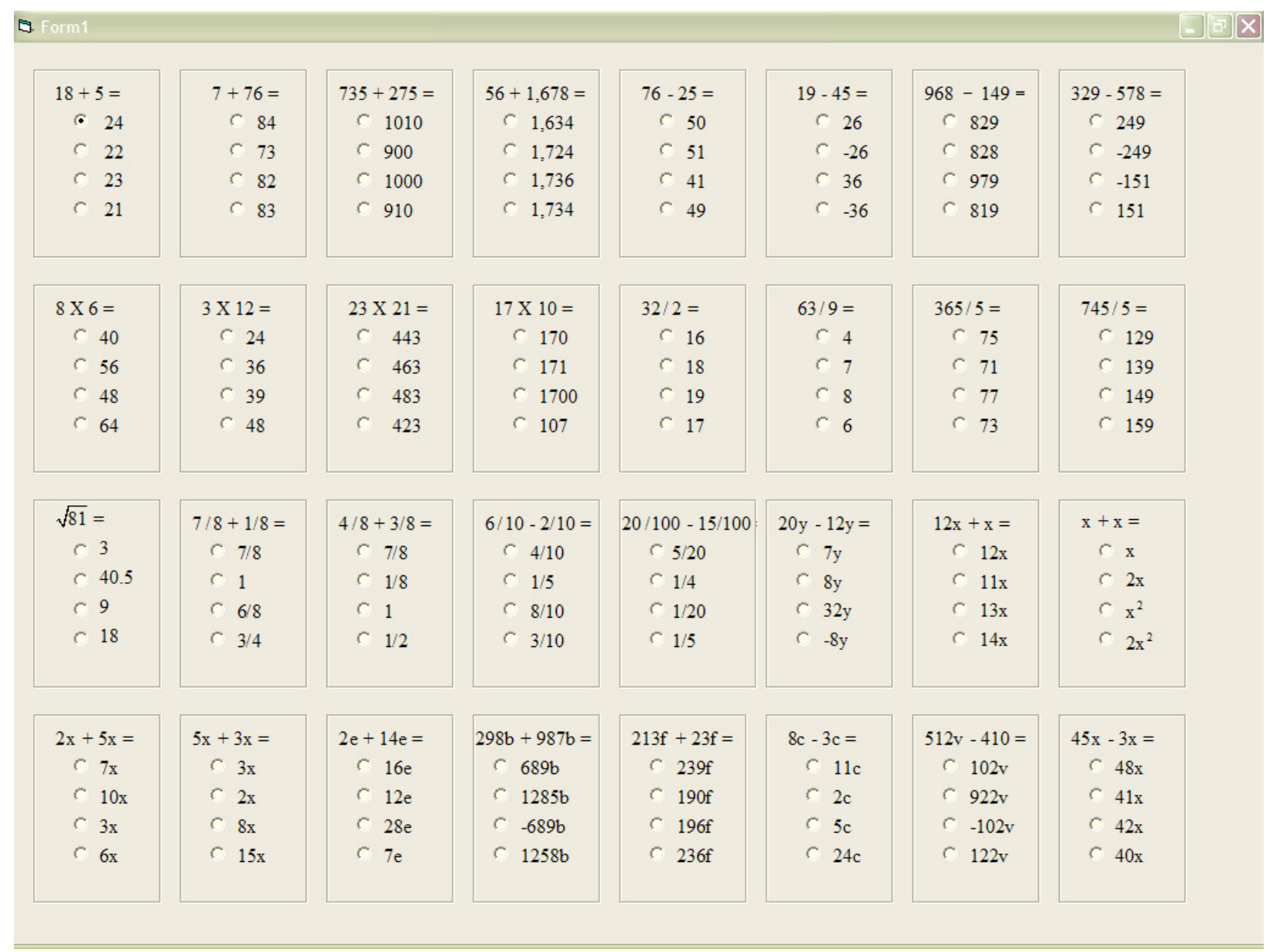


Feedback and reinforcement 71

\section{Appendix C: Sample Exponent pretest}
$8 e^{4} \cdot 5 e^{7}=$
$9 v^{3} \cdot 8 v^{3}=$
$\left(8 r^{9}\right)\left(2 r^{6}\right)=$
$3 u^{8} \cdot 5 u^{9}=$
$2^{3} g^{5} \cdot 2^{8} g=$
$\left(4^{9} y^{3}\right)^{9}=$
$\frac{27 a^{7}}{9 a^{6}}=$
$\frac{21 t^{13}}{7 t^{7}}=$
$\frac{8^{14} w^{6}}{8^{5} w^{2}}=$
$\frac{10 m^{15}}{5 m^{6}}=$
$\frac{32 u^{12}}{8 u^{11}}=$
$\left(2 h^{1}\right)^{6}=$
$\left(2 y^{3}\right)^{3}=$
$(5 k)^{9}=$
$\left(2^{7} x^{3}\right)^{6}=$
$\frac{8+8}{12-8}=$
$(14-7)^{2}=$
$(12-9)^{2}+4=$
$\sqrt{(14-6)+8}=$
$\sqrt{\frac{18-9}{3}+6}=$
$\sqrt[8]{6^{64} q^{24}}=$
$\sqrt[4]{8^{28} k^{16}}=$
$\sqrt{1^{14} f^{6}}=$
$\sqrt[6]{3^{18} m^{36}}=$
$\sqrt[5]{2^{15} a^{20}}=$ 
Feedback and reinforcement 72

\section{Appendix D: Sample Adduction test}
$\left(\frac{21 b^{11}}{3 b^{4}}\right)^{2}=$
$\left(8 x^{2} \cdot 7 x^{7}\right)^{9}=$
$\frac{\sqrt{8^{2} k^{6}}}{4 k}=$
$\sqrt[7]{5^{9} d^{5} \cdot 5^{5} d^{9}}=$
$\sqrt[6]{3^{3} j^{9} \cdot 3^{9} j^{9}}=$
$\frac{7^{9} h^{9}}{\sqrt[3]{7^{21} h^{18}}}=$
$\left(3^{3} g^{4} \cdot 3^{5} g^{5}\right)^{6}=$
$\left(\frac{36 n^{16}}{4 n^{9}}\right)^{8}=$
$\left(\frac{4 a^{3} \cdot 5 a^{5}}{2 a^{4}}\right)^{5}=$
$\left(\frac{\sqrt[3]{4^{6} y^{12}}}{4 y^{2}}\right)^{7}=$
$\sqrt[4]{\left(9 h^{2} \cdot 6 h^{1}\right)^{8}}=$
$\frac{\sqrt[5]{18^{5} f^{25}}}{2 f^{2} \cdot 3 f^{2}}=$
$\left(\frac{40 m^{11}}{2 m^{0} \cdot 4 m^{5}}\right)^{8}=$
$\left(\frac{25 t^{10}}{\sqrt[4]{5^{4} t^{20}}}\right)^{7}=$
$\sqrt[4]{\left(5 d^{3} \cdot 5^{3} d\right)^{7}}=$
$\frac{8^{6} y^{9} \cdot 8^{9} y^{5}}{\sqrt{8^{16} y^{14}}}=$
$\left(\frac{\sqrt[4]{36^{4} g^{12}}}{3 g^{1} \cdot 3 g}\right)^{9}=$
$\sqrt[3]{\frac{\left(3 h^{1} \cdot 3 h^{2}\right)^{6}}{h^{9}}}=$
$\frac{\sqrt{2^{4} t^{10}} \cdot\left(2 t^{4}\right)^{2}}{2 t^{5}}=$
$\frac{\left(3^{4} m^{6}\right)^{3}}{m^{9}} \cdot \sqrt[5]{1^{5} m^{45}}=$
$\left(\frac{7 f^{5} \cdot 5 f^{3}}{\sqrt{5^{2} f^{12}}}\right)^{6}=$
$\sqrt[2]{\frac{\left(4 g^{0} \cdot 5 g^{4}\right)^{3}}{20 g^{6}}}=$
$\frac{\sqrt[9]{6^{18} k^{27}} \cdot\left(6^{2} k^{2}\right)^{4}}{6^{4} k^{7}}=$
$\frac{\left(8 b^{3}\right)^{6}}{8^{4} b^{9}} \cdot \sqrt[6]{8^{48} b^{54}}=$
$\sqrt[2]{\frac{\left(6 a^{4}\left[2 a^{6}\right)^{5}\right.}{12 a^{10}}}=$ 


\section{Appendix E: Sample Rule screen}

\section{Rule 1}

Variables are letters that stand for numbers. It is like putting a blank when you don't know what a certain number is. For example, you can write $2+\ldots=3$, or you can use a letter, like $x$, instead of a _ , so you could write $2+x=3$. You can use any letter of the alphabet as a variable.

Exponents are a way of saying how many times you need to multiply a number by itself. An exponent is written small and is at the top right of a number. So if you have $2^{3}$, the 3 is the exponent, and the 2 is called the base. If you want to solve $2^{3}$, it is the same as $2 \cdot 2 \cdot 2$, or (2)(2)(2), or " 2 times 2 times 2 ".

Variables can have exponents, too. So if you see $a^{4}$, it is the same as $(a)(a)(a)(a)$ If you see a base or variable by itself, then the exponent is 1 . So $b=b^{1}$, and $5 t=5^{1} t^{1}$

To multiply variables with exponents, $\mathrm{ADD}$ the exponents.

Examples: $\quad a^{2} \cdot a^{3}=(a \cdot a) \cdot(a \cdot a \cdot a)=a^{5}$ or $a^{2+3}=a^{5}$

$$
\begin{aligned}
& x^{5} \cdot x^{9}=x^{14} \\
& \left(g^{3}\right)(g)=\left(g^{3}\right)\left(g^{1}\right)=g^{4} \\
& a^{1} \cdot a^{3}=a \cdot(a \cdot a \cdot a)=a^{4}
\end{aligned}
$$

If the variables have bases in front, MULTIPLY the bases as you would in a regular multiplication problem.

Examples: $\quad 3 x^{5} \cdot 7 x \Rightarrow 3 \cdot 7=21 ; x^{5} \cdot x^{1}=(x \cdot x \cdot x \cdot x \cdot x)(x)=x^{6} \Rightarrow 21 x^{6}$

$$
\left(t^{3}\right)\left(4 t^{5}\right)=\left(1 t^{3}\right)\left(4 t^{5}\right)=4 t^{8}
$$

BUT, if the bases are the SAME number, LEAVE THE BASE THE SAME, and ADD the exponents just like you do for the variables

Examples: $\quad\left(2^{4} g^{3}\right)\left(2^{5} g\right)=\left(2^{4} g^{3}\right)\left(2^{5} g^{1}\right)=2^{9} g^{4}$

$$
5^{3} y^{3} \cdot 5 y^{4}=5^{3} y^{3} \cdot 5^{1} y^{4}=5^{4} y^{7}
$$




\section{Appendix F: Sample Timing Worksheet}

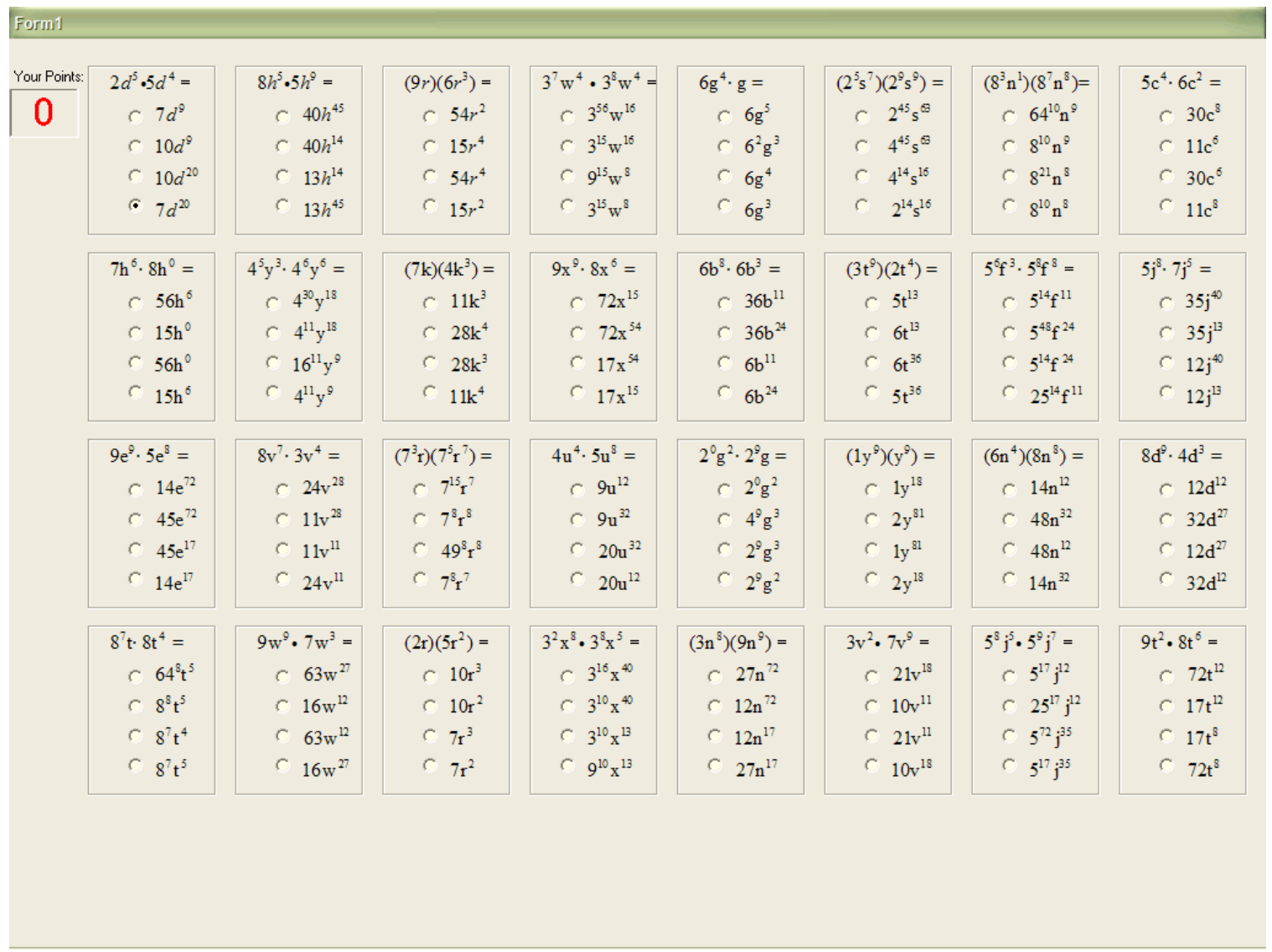


Feedback and reinforcement 75

\section{Appendix G: Sample Disruption test}

\begin{tabular}{|c|c|c|c|}
\hline $\begin{array}{c}\left(3 \mathrm{n}^{8}\right)\left(9 \mathrm{n}^{9}\right)= \\
\sim 27 \mathrm{n}^{72} \\
\sim 12 \mathrm{n}^{72} \\
\sim 12 \mathrm{n}^{17} \\
\sim 27 \mathrm{n}^{17}\end{array}$ & $\begin{array}{c}(2 \mathrm{r})\left(5 \mathrm{r}^{2}\right)= \\
\sim 10 \mathrm{r}^{3} \\
\sim 10 \mathrm{r}^{2} \\
\sim 7 \mathrm{r}^{3} \\
\sim 7 \mathrm{r}^{2}\end{array}$ & 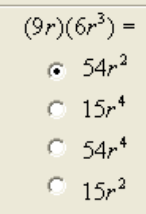 & $\begin{array}{l}8^{7} \mathrm{t} \cdot 8 \mathrm{t}^{4}= \\
\sim 64^{8} \mathrm{t}^{5} \\
\sim 8^{8} \mathrm{t}^{5} \\
\sim 8^{7} \mathrm{t}^{4} \\
\sim 8^{7} \mathrm{t}^{5}\end{array}$ \\
\hline $\begin{array}{r}7 \mathrm{~h}^{6} \cdot 8 \mathrm{~h}^{0}= \\
\sim 56 \mathrm{~h}^{6} \\
\sim 15 \mathrm{~h}^{0} \\
\sim 56 \mathrm{~h}^{0} \\
\sim 15 \mathrm{~h}^{6}\end{array}$ & $\begin{array}{c}4^{5} y^{3} \cdot 4^{6} y^{6}= \\
\sim 4^{30} y^{18} \\
r 4^{11} y^{18} \\
r \quad 16^{11} y^{9} \\
\sim 4^{11} y^{9}\end{array}$ & $\begin{array}{l}(7 \mathrm{k})\left(4 \mathrm{k}^{3}\right)= \\
\sim 11 \mathrm{k}^{3} \\
\sim 28 \mathrm{k}^{4} \\
\sim 28 \mathrm{k}^{3} \\
\sim 11 \mathrm{k}^{4}\end{array}$ & $\begin{array}{c}9 x^{9} \cdot 8 x^{6}= \\
\sim 72 x^{15} \\
\sim 72 x^{54} \\
\sim 17 x^{44} \\
\sim 17 x^{15}\end{array}$ \\
\hline $\begin{array}{c}9 \mathrm{e}^{9} \cdot 5 \mathrm{e}^{8}= \\
\left\ulcorner 14 \mathrm{e}^{72}\right. \\
\left\ulcorner 45 \mathrm{e}^{72}\right. \\
\left\ulcorner 45 \mathrm{e}^{17}\right. \\
\left\ulcorner 14 \mathrm{e}^{17}\right.\end{array}$ & $\begin{array}{l}8 \mathrm{v}^{7} \cdot 3 \mathrm{v}^{4}= \\
\left\ulcorner 24 \mathrm{v}^{28}\right. \\
\sim 11 \mathrm{v}^{28} \\
\left\ulcorner 11 \mathrm{v}^{11}\right. \\
\left\ulcorner 24 \mathrm{v}^{11}\right.\end{array}$ & $\begin{array}{c}\left(7^{3} \mathrm{r}\right)\left(7^{5} \mathrm{r}^{7}\right)= \\
\sim 7^{15} \mathrm{r}^{7} \\
\sim 7^{8} \mathrm{r}^{8} \\
\sim 49^{8} \mathrm{r}^{8} \\
\sim 7^{8} \mathrm{r}^{7}\end{array}$ & $\begin{array}{c}4 u^{4} \cdot 5 u^{8}= \\
\sim 9 u^{12} \\
\sim 9 u^{32} \\
\sim 20 u^{32} \\
\sim 20 u^{12}\end{array}$ \\
\hline $\begin{array}{c}5 c^{4} \cdot 6 c^{2}= \\
<30 c^{8} \\
\sim 11 c^{6} \\
<30 c^{6} \\
>11 c^{8}\end{array}$ & $\begin{array}{l}5 j^{8} \cdot 7 j^{5}= \\
\sim 35 j^{40} \\
\sim 35 j^{13} \\
\sim 12 j^{40} \\
>12 j^{13}\end{array}$ & $\begin{array}{l}8 \mathrm{~d}^{9} \cdot 4 \mathrm{~d}^{3}= \\
\sim 12 \mathrm{~d}^{12} \\
\sim 32 \mathrm{~d}^{27} \\
\sim 12 \mathrm{~d}^{2} \\
>32 \mathrm{~d}^{12}\end{array}$ & $\begin{array}{c}(6 r)\left(3 r^{8}\right)= \\
\sim 18 r^{8} \\
r 9 r^{8} \\
\sim 18 r^{9} \\
\text { r } 9 r^{9}\end{array}$ \\
\hline
\end{tabular}

\begin{tabular}{|c|c|c|}
\hline $\begin{array}{c}6 \mathrm{~g}^{4} \cdot \mathrm{g}= \\
\sim 6 \mathrm{~g}^{5} \\
\sim 6^{2} \mathrm{~g}^{3} \\
\sim 6 \mathrm{~g}^{4} \\
\sim 6 \mathrm{~g}^{3}\end{array}$ & $\begin{array}{c}\left(2^{5} s^{7}\right)\left(2^{9} s^{9}\right)= \\
r \quad 2^{45} s^{63} \\
r \quad 4^{45} s^{63} \\
r \quad 4^{14} s^{16} \\
r \quad 2^{14} s^{16}\end{array}$ & $\begin{array}{c}\left(8^{3} n^{1}\right)\left(8^{7} n^{8}\right)= \\
r 64^{10} n^{9} \\
\sim 8^{10} n^{9} \\
\sim 8^{21} n^{8} \\
\sim 8^{10} n^{8}\end{array}$ \\
\hline $\begin{array}{c}6 \mathrm{~b}^{8} \cdot 6 \mathrm{~b}^{3}= \\
\sim 36 \mathrm{~b}^{11} \\
\sim 36 \mathrm{~b}^{24} \\
\sim 6 \mathrm{~b}^{11} \\
\sim 6 \mathrm{~b}^{24}\end{array}$ & $\begin{array}{c}\left(3 t^{9}\right)\left(2 t^{4}\right)= \\
\sim 5 t^{13} \\
\sim 6 t^{13} \\
\sim 6 t^{36} \\
\sim 5 t^{36}\end{array}$ & 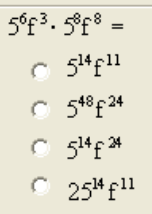 \\
\hline $\begin{array}{r}2^{0} \mathrm{~g}^{2} \cdot 2^{9} \mathrm{~g}= \\
\left\ulcorner 2^{0} \mathrm{~g}^{2}\right. \\
\sim 4^{9} \mathrm{~g}^{3} \\
\sim 2^{9} \mathrm{~g}^{3} \\
\sim 2^{9} \mathrm{~g}^{2}\end{array}$ & $\begin{array}{c}\left(1 y^{9}\right)\left(y^{9}\right)= \\
\sim 1 y^{18} \\
\sim 2 y^{81} \\
\sim 1 y^{81} \\
\sim 2 y^{18}\end{array}$ & $\begin{array}{c}\left(6 n^{4}\right)\left(8 n^{8}\right)= \\
\sim 14 n^{12} \\
\left\ulcorner 48 n^{32}\right. \\
\left\ulcorner 48 n^{12}\right. \\
\sim 14 n^{32}\end{array}$ \\
\hline
\end{tabular}

